\title{
Disparidades fiscales regionales en el Uruguay: el rol de un nuevo sistema de transferencias intergubernamentales ecualizadoras
}

\author{
Leonel Muinelo-Gallo, Joana Urraburu Bordon \\ y Pablo Castro Scavone
}

\section{Resumen}

En este artículo se analiza el rol de las transferencias intergubernamentales a partir de un análisis empírico aplicado a un grupo de regiones (departamentos) del Uruguay durante el período 2006-2014. Se examina la estructura y evolución de las disparidades fiscales regionales y los efectos ecualizadores del actual sistema de transferencias. Luego, se propone una metodología novedosa que permite simular los efectos de la implementación de un nuevo sistema de transferencias de tipo ecualizador. El principal resultado muestra que la implementación de este nuevo sistema de transferencias ecualizadoras contribuye a consolidar un territorio con un mayor nivel de homogeneidad fiscal territorial en el Uruguay.

\section{Palabras clave}

Política fiscal, administración fiscal, desigualdades regionales, ingresos fiscales, desarrollo regional, Uruguay

\section{Clasificación JEL}

C33, $\mathrm{H} 77, \mathrm{R} 11$

\section{Autores}

Leonel Muinelo-Gallo es profesor agregado a tiempo completo en el Instituto de Economía de la Facultad de Ciencias Económicas y Administración de la Universidad de la República (Uruguay). Correo electrónico: Imuinelo@iecon.ccee.edu.uy.

Pablo Santiago Castro Scavone es asistente de investigación en el Instituto de Economía de la Facultad de Ciencias Económicas y Administración de la Universidad de la República (Uruguay). Correo electrónico: pcastro@iecon.ccee.edu.uy.

Joana Urraburu Bordon es profesora ayudante en el Instituto de Economía de la Facultad de Ciencias Económicas y Administración de la Universidad de la República (Uruguay). Correo electrónico: jurraburu@iecon.ccee.edu.uy. 


\section{Introducción}

En el presente artículo se analiza el rol macroeconómico de las transferencias intergubernamentales a través de un análisis empírico aplicado al Uruguay.

Uno de los objetivos fundamentales de las transferencias intergubernamentales consiste en reducir los desequilibrios fiscales entre unidades de gobierno del mismo nivel. Más específicamente, disminuir o eliminar las diferencias que pudieran existir en cuanto a la capacidad de generar recursos propios y en lo referente a los gastos ejecutados - ambos expresados en términos per cápita- entre unidades del mismo nivel de gobierno (por ejemplo, entre los diferentes gobiernos subnacionales).

Las transferencias intergubernamentales son una herramienta sumamente importante para promover la cohesión fiscal regional en los países desarrollados. El modelo de cohesión territorial de la Unión Europea, que se plasma en su programa "Fondos Estructurales y de Inversión Europeos", es un claro ejemplo de ello (Böhme, 2009). A su vez, la mayoría de los países de la Organización para la Cooperación y el Desarrollo Económicos (OCDE) emplean programas redistributivos con el objeto de reducir las disparidades fiscales a nivel regional. Es así como, en promedio, esos países logran reducir más de dos terceras partes de sus disparidades fiscales regionales (Martínez-Vázquez, 2015). De hecho, la importancia del diseño de un sistema de transferencias de tipo ecualizador radica en que un territorio con una mayor homogeneidad fiscal permite alcanzar un umbral mínimo de provisión de servicios públicos subnacionales de calidad similar, evitando de esta forma migraciones ineficientes de recursos en el territorio nacional (Martínez-Vázquez y Sepúlveda, 2011). De igual manera, este sistema ecualizador es capaz de brindar un respaldo importante a una agenda ordenada de los procesos de descentralización fiscal. Por último, una mayor cohesión fiscal da lugar a un desarrollo territorial más equilibrado, con una desconcentración del poder político y de la actividad económica (Martínez-Vázquez y Sepúlveda, 2012).

A partir de la reforma constitucional de 1996, en el Uruguay se viene impulsando un proceso que busca avanzar hacia un mayor grado de descentralización territorial ${ }^{1}$. Resulta importante tener en cuenta que este proceso podría conducir a un incremento de las disparidades fiscales horizontales (rezagando a aquellos gobiernos subnacionales con altas necesidades de gastos o reducidas fuentes de recursos propios). De hecho, aunque el Uruguay es un país pequeño, existen diferencias fiscales importantes entre sus diferentes gobiernos departamentales. El mapa 1 muestra esas disparidades, considerando los distintos gastos per cápita ejecutados por los 19 gobiernos departamentales en el período objeto de análisis ${ }^{2}$.

Una mirada al mapa 1 pone de manifiesto diferencias importantes en términos de gastos per cápita. En este contexto, y dado que todos los gobiernos departamentales del Uruguay deben brindar exactamente los mismos servicios públicos, dichas diferencias deberían tener efectos significativos sobre la cantidad y calidad de los servicios públicos prestados por cada uno de esos gobiernos.

\footnotetext{
1 De todas formas, el Uruguay sigue siendo un país fuertemente centralizado. Durante el período objeto de análisis (20062014), cerca del $90 \%$ del gasto público fue realizado directamente por el gobierno central, mientras que a los gobiernos departamentales correspondió solamente el $10 \%$ de la ejecución del gasto.

2 El Uruguay se divide en 19 departamentos, que son el segundo nivel de gobierno luego del gobierno central. Véase en detalle la división política de Uruguay en el anexo A1.
} 


\section{Mapa 1}

Uruguay: gastos per cápita de los gobiernos departamentales, promedio de 2006-2014

(En pesos uruguayos de 2014)

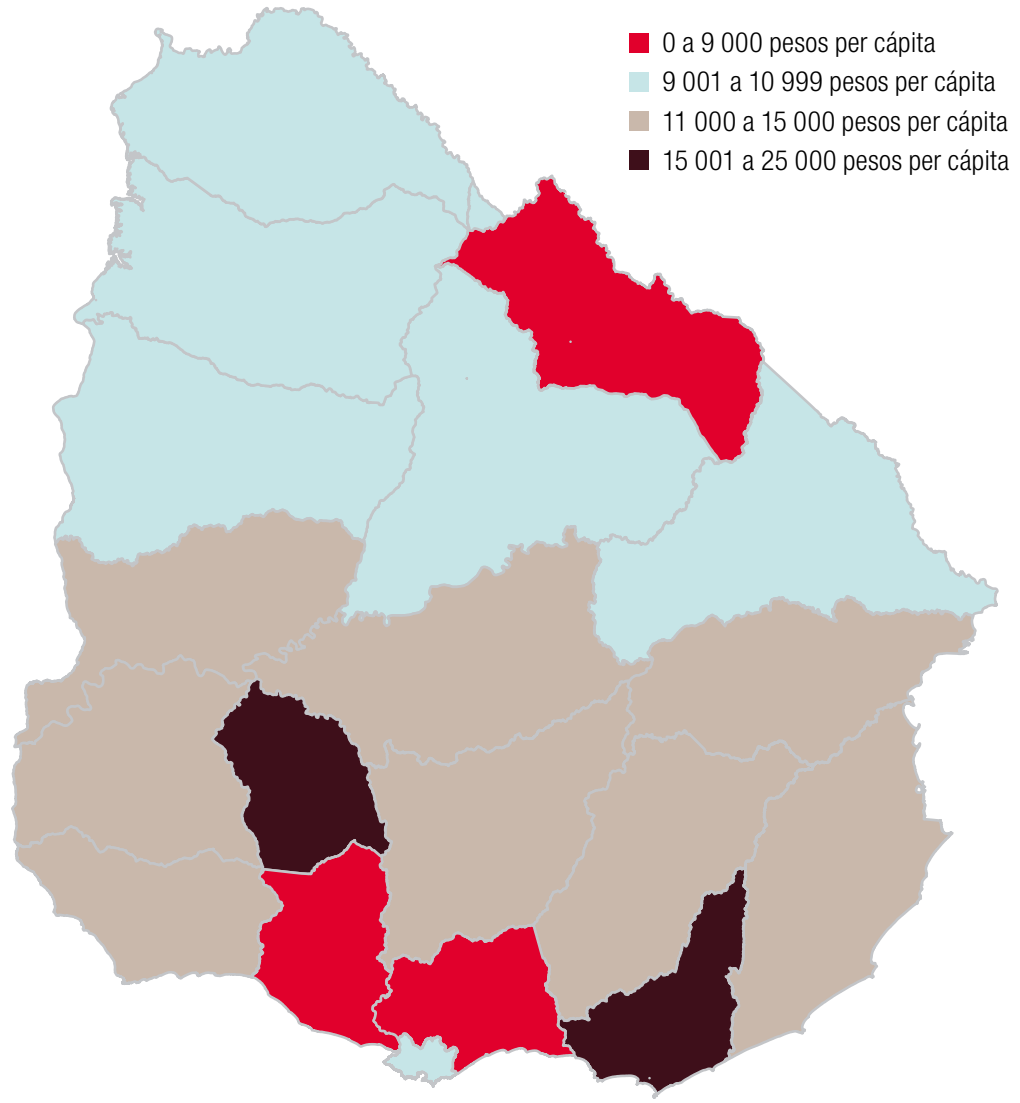

Fuente: Oficina de Planeamiento y Presupuesto de la Presidencia de la República (OPP), sobre la base de rendiciones de cuentas de los gobiernos departamentales.

Teniendo en cuenta el contexto, en este artículo se analiza el efecto de las transferencias intergubernamentales en las disparidades fiscales regionales a partir de un análisis empírico aplicado al grupo de 19 departamentos del Uruguay durante el período 2006-2014. Con la información estadística disponible, hemos de limitar nuestro análisis a este período, dado que el gobierno departamental de Montevideo comenzó a recibir transferencias del gobierno central a partir de 2006. A pesar de ello, se trata de un período de nueve años que consideramos lo suficientemente extenso como para evaluar las relaciones propuestas en el presente artículo.

En el artículo se realizan dos tipos de análisis. En primer lugar, se evalúa el impacto ecualizador del sistema de transferenciales intergubernamentales actualmente vigente en el Uruguay. En segundo lugar, se proponen y discuten los efectos de la implementación de un nuevo sistema de transferencias de tipo ecualizador en el país.

Creemos que la investigación aquí propuesta se justifica por dos razones fundamentales. En primer lugar, por la carencia de trabajos previos que analicen de forma adecuada dichas relaciones fiscales regionales para el caso de un país de ingreso medio como el Uruguay. En segundo lugar, porque a raíz del correcto tratamiento empírico de la información estadística disponible será posible examinar las implicancias fundamentales de un diseño óptimo de las estructuras fiscales subnacionales en el país. 
El trabajo se estructura de la siguiente forma. En la sección II, se discuten los estudios que han analizado tanto los factores determinantes de los diferentes regímenes de transferencias gubernamentales como los eventuales efectos que las transferencias intergubernamentales pudieran tener sobre las disparidades regionales. En la sección III, se analiza el actual sistema de relaciones fiscales intergubernamentales del Uruguay, tras lo cual, en la sección IV, se evalúan los efectos ecualizadores de dicho sistema. En la sección V, se elabora, por primera vez para el Uruguay, una novedosa metodología que permite simular los efectos de la implementación de un nuevo sistema de transferencias de tipo ecualizador. Por último, en la sección VI, se presentan unas breves conclusiones y recomendaciones de política.

\section{Disparidades regionales y transferencias intergubernamentales}

La literatura tradicional sobre finanzas públicas regionales brinda una guía normativa acerca de cómo se deberían distribuir las transferencias intergubernamentales para poder mejorar tanto la eficiencia en la provisión de bienes públicos locales como la igualdad en la asignación de recursos dentro de un país (Musgrave, 1959; Oates, 1972).

En la búsqueda del objetivo de eficiencia, el régimen de transferencias debería corregir la subprestación de ciertos servicios públicos locales. Dado que no todos los beneficios de la provisión de estos servicios pueden ser aprovechados por los gobiernos subnacionales o regionales, estos gobiernos locales podrían tender a prestar de forma insuficiente ciertos servicios públicos locales (por ejemplo, educación). Como resultado de ello, y ante la presencia de externalidades positivas en la provisión de estos servicios locales, en aras de la eficiencia económica el gobierno central podría realizar mayores transferencias intergubernamentales en respuesta a las mayores necesidades en materia de gastos locales (por ejemplo, esas necesidades se podrían ver reflejadas por el número de niños en edad escolar de cada región).

El segundo objetivo normativo es lograr una distribución equitativa de los recursos públicos entre la población nacional. Así, las políticas que garanticen un acceso igualitario a nivel regional de los servicios públicos subnacionales a menudo se implementan a través de sistemas de transferencias ecualizadoras. Dentro de este marco, destaca el papel que cumplen las transferencias intergubernamentales de tipo ecualizador en tanto coadyuvan a cubrir las necesidades fiscales de las regiones fiscalmente rezagadas (Martínez-Vázquez y Sepúlveda, 2012). Más específicamente, es el principio de equidad interjurisdiccional el que brinda racionalidad económica a este sistema de transferencias ecualizadoras. Según una formulación general de este principio, las personas en circunstancias comparables deberían tener acceso a servicios públicos similares en todas las localidades geográficas de determinado territorio (Boadway, 2015; Brosio y Jiménez, 2015; Muñoz y Radics, 2016). El marco de equidad de las transferencias intergubernamentales implica que la residencia geográfica no debe crear diferencias entre los ciudadanos, ni en el acceso a los servicios públicos ni en su costo unitario. En este contexto, en los sistemas de igualación interjurisdiccional más avanzados (por ejemplo, el del Canadá), la equidad se alcanza cuando a través de transferencias intergubernamentales de tipo ecualizador se proporciona a los gobiernos subnacionales ingresos suficientes para asegurar que las personas en circunstancias similares puedan tener acceso a servicios públicos comparables en todas las localidades geográficas.

De forma reciente, un grupo cada vez mayor de trabajos han analizado empíricamente tanto los principales factores determinantes como los efectos regionales de las transferencias intergubernamentales ${ }^{3}$. Por ejemplo, Muinelo-Gallo, Rodríguez y Castro (2016) evalúan el efecto

\footnotetext{
3 Véanse Solé-Ollé y Sorribas-Navarro (2008) y Curto-Grau, Solé-Ollé y Sorribas-Navarro (2012) como ejemplos de países de ingreso alto.
} 
de diferentes variables económicas, demográficas y políticas sobre el nivel de transferencias intergubernamentales per cápita en el Uruguay. Los autores señalan que el nivel de esas transferencias se ve positivamente afectado por el nivel de gasto público ejecutado en el pasado por los gobiernos regionales y negativamente afectado por el tamaño poblacional de las regiones (departamentos). El primer resultado podría reflejar el impacto de las necesidades fiscales de los gobiernos departamentales, pero también podría evidenciar la capacidad de negociación de esos gobiernos cuando demandan recursos del gobierno central a través de transferencias regionales. El efecto negativo de la población departamental podría ser una respuesta a la presencia de economías de escala en la prestación de servicios públicos subnacionales, o podría explicarse por el poder de presión potencialmente desproporcionado que tienen las jurisdicciones subnacionales más pequeñas. Sus estimaciones también ponen de manifiesto que las desigualdades regionales tienen un impacto importante y negativo sobre las transferencias. Este último resultado también se refleja en el hecho de que el valor del PIB per cápita del departamento tiene un efecto positivo y considerable en las transferencias intergubernamentales. Por último, los autores no detectan un impacto sustancial de las transferencias sobre la reducción de las desigualdades económicas regionales. En el Uruguay esas transferencias intergubernamentales no tienen un efecto igualador regional significativo.

\section{El sistema de relaciones fiscales intergubernamentales vigente en el Uruguay}

\section{Recursos y servicios públicos regionales}

Las atribuciones formalmente asignadas a los gobiernos departamentales en el Uruguay, que constituyen el segundo nivel de gobierno, se definen en la ley fundamental de gobierno y administración de los departamentos (Ley núm. 9.515), que no ha sufrido modificaciones desde 1935. En este marco, los gobiernos departamentales del Uruguay tienen a su cargo la realización de actividades de carácter típicamente municipal (conforme a la experiencia internacional). Más específicamente, las competencias formales se reducen a la prestación de los servicios básicos: pavimento y mantenimiento de caminos; organización del tránsito (incluyendo la recaudación de patentes de vehículos y licencias de conducir); transporte colectivo; limpieza; iluminación pública; servicio de necrópolis; controles sanitarios, y ordenamiento territorial.

A su vez, los recursos fiscales con los que cuentan los gobiernos departamentales se pueden clasificar en dos grandes categorías:

i) Ingresos propios: los de origen departamental ${ }^{4}$, o los impuestos que son fijados por el gobierno central pero cuya recaudación y utilización corresponden a los gobiernos departamentales 5 .

ii) Transferencias desde el gobierno central hacia los gobiernos departamentales. Estas transferencias pueden ser de dos tipos: condicionadas o no condicionadas.

\footnotetext{
4 Los principales ingresos propios son: contribución inmobiliaria sobre inmuebles urbanos y suburbanos, patente de rodados, impuestos de menor magnitud (impuesto a los terrenos baldíos y edificación inapropiada y contribuciones por mejoras a los inmuebles beneficiados por obras públicas), tasas, tarifas, beneficios y precios por utilización de bienes o servicios departamentales.

5 Entre estos destacan el impuesto sobre la propiedad inmueble rural y el impuesto sobre la venta de semovientes (Ley 12.700 de 1960).
} 


\section{El marco normativo que regula el régimen de transferencias regionales en el Uruguay}

De las dos fuentes de ingresos por transferencias de los gobiernos departamentales del Uruguay, las de menor magnitud son las transferencias condicionadas (estas representan transferencias menores de los diferentes ministerios del gobierno central: Ministerio de Transporte y Obras Públicas, Ministerio de Turismo y otros organismos públicos). La gran mayoría de los ingresos departamentales de origen nacional (el 90\%) provienen de transferencias no condicionadas. En el cuadro 1 se detalla la composición de las transferencias intergubernamentales, por departamento y según su grado de condicionamiento.

Cuadro 1

Uruguay: composición de los ingresos por transferencias intergubernamentales por gobierno departamental, promedio de 2006-2014

(A precios constantes de 2014)

\begin{tabular}{|c|c|c|c|c|}
\hline \multirow{2}{*}{ Departamento } & \multicolumn{2}{|c|}{ Transferencias condicionadas } & \multicolumn{2}{|c|}{ Transferencias no condicionadas } \\
\hline & $\begin{array}{l}\text { (en miles de } \\
\text { pesos 2014) }\end{array}$ & $\begin{array}{c}\text { (en porcentaje del PIB } \\
\text { del departamento) }\end{array}$ & $\begin{array}{l}\text { (en miles de } \\
\text { pesos 2014) }\end{array}$ & $\begin{array}{c}\text { (en porcentaje del PIB } \\
\text { del departamento) }\end{array}$ \\
\hline Artigas & 51117 & 0,302 & 352560 & 2,130 \\
\hline Canelones & 91023 & 0,084 & 836011 & 0,808 \\
\hline Cerro Largo & 70281 & 0,343 & 422327 & 2,043 \\
\hline Colonia & 45775 & 0,085 & 316667 & 0,607 \\
\hline Durazno & 32937 & 0,226 & 378029 & 2,524 \\
\hline Flores & 26529 & 0,304 & 188317 & 2,245 \\
\hline Florida & 42757 & 0,197 & 321186 & 1,536 \\
\hline Lavalleja & 30810 & 0,184 & 346930 & 1,873 \\
\hline Maldonado & 213865 & 0,329 & 511705 & 0,858 \\
\hline Montevideo & 508798 & 0,084 & 1064770 & 0,190 \\
\hline Paysandú & 49369 & 0,161 & 454127 & 1,444 \\
\hline Río Negro & 108262 & 0,380 & 300256 & 1,165 \\
\hline Rivera & 68412 & 0,312 & 391290 & 1,682 \\
\hline Rocha & 8877 & 0,055 & 420386 & 2,022 \\
\hline Salto & 62376 & 0,218 & 492114 & 1,684 \\
\hline San José & 32483 & 0,103 & 309951 & 1,008 \\
\hline Soriano & 35591 & 0,142 & 381748 & 1,520 \\
\hline Tacuarembó & 8838 & 0,050 & 424911 & 1,928 \\
\hline Treinta y Tres & 26645 & 0,183 & 335870 & 2,368 \\
\hline
\end{tabular}

Fuente: Oficina de Planeamiento y Presupuesto de la Presidencia de la República (OPP), sobre la base de rendiciones de cuentas de los gobiernos departamentales.

A pesar de que las transferencias intergubernamentales están definidas en la Ley de Presupuesto Nacional, durante los diferentes períodos de gobierno analizados (2006-2014) se promulgaron leyes que añadieron elementos suplementarios a la legislación sobre transferencias. En muchos casos estas transferencias adicionales se justificaron por circunstancias particulares, como crisis financieras en determinados gobiernos departamentales, sequías o inundaciones. Sin embargo, con frecuencia estas transferencias ocasionales terminaron convirtiéndose en partidas permanentes a raíz de la presión de los gobiernos departamentales por mantener, o incluso aumentar, los recursos en el próximo período de gobierno (Muinelo-Gallo, Rodríguez y Castro, 2016). 
En la Ley de Presupuesto Nacional para los períodos 2001-2005 y 2006-2010 se incorporaron las reformas a la Constitución Nacional realizadas en 1996. Dentro de este marco, se esperaba mejorar el sistema de transferencias y evitar las transferencias adicionales (sobre una base ad hoc) no incluidas en la Ley de Presupuesto Nacional. Esta nueva Constitución Nacional estableció dos tipos de mecanismos de transferencias, que se establecen en los artículos 214 y 298.

El artículo 214 estipula que en cada período de gobierno debe distribuirse una alícuota del presupuesto nacional total entre los gobiernos departamentales. Esta alícuota era del 3,18\% en 2001 y fue aumentando progresivamente hasta alcanzar el 3,54 \% en 2005, fijándose en el 3,33 \% a partir de 2006. Una parte importante de esta alícuota es financiada por los programas de infraestructura municipal y mantenimiento de caminos rurales (ambos administrados por el gobierno central). Los fondos remanentes se distribuyen entre los gobiernos departamentales en función de dos criterios. Uno de ellos se basa en indicadores de población, superficie, inversa del PIB regional y porcentaje de hogares con necesidades insatisfechas ( $25 \%$ cada uno). El otro criterio se basa en la distribución porcentual entre los gobiernos departamentales en el período gubernamental anterior. El resultado final de distribución de estas transferencias se deriva de algún tipo de promedio entre los dos criterios, aunque su distribución final no resulta para nada clara. A su vez, el porcentaje de fondos remanentes (publicado en las leyes de presupuestos nacionales núm. 17.296 para 2001-2005 y núm. 17.930 para 2006-2014) queda determinado por la negociación política entre el gobierno central y el Congreso de Intendentes de los gobiernos departamentales ${ }^{6}$.

El otro artículo de la Constitución Nacional que regula las transferencias intergubernamentales es el núm. 298, referente al Fondo de Desarrollo del Interior (FDI). Los objetivos del FDI son el desarrollo local y regional y la descentralización. Este fondo está formado por una alícuota (cerca del $11 \%$ ) de los impuestos que el gobierno central recauda de los diferentes departamentos del país, excluido Montevideo. Sin embargo, solo el 33,5\% de la financiación del FDI se dirige directamente a los gobiernos departamentales, mientras que el $66,5 \%$ restante es ejecutado directamente por el gobierno central.

En suma, en los diferentes gobiernos del período 2006-2014 la asignación de transferencias intergubernamentales en el Uruguay estuvo compuesta por mecanismos poco claros, con algunos criterios orientadores pero que distaban mucho de ser de fórmulas claras y técnicamente definidas, y con un grado implícito de negociación política importante entre el gobierno central y los gobiernos departamentales. Al mismo tiempo, la mayoría de los criterios de asignación de transferencias - población, superficie e incluso PIB per cápita-llevaban aparejado un componente de inercia temporal, además de la consideración explícita de cómo se habían asignado los recursos entre los gobiernos departamentales en el último período de gobierno anterior. En este sentido, se puede señalar que la equidad fiscal no parece haber desempeñado un rol destacado en el régimen de transferencias intergubernamentales actualmente vigente en el Uruguay.

En el cuadro 2 se presentan los ingresos de los gobiernos departamentales y se calculan diferentes medidas de desigualdad fiscal entre ellos. Este análisis nos permite realizar una aproximación preliminar a los eventuales efectos ecualizadores del sistema de transferencias actualmente vigente en el Uruguay.

\footnotetext{
6 Este Congreso fue establecido por la Constitución de 1996 como un consejo representativo de los gobiernos departamentales.
} 


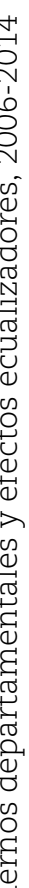

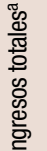

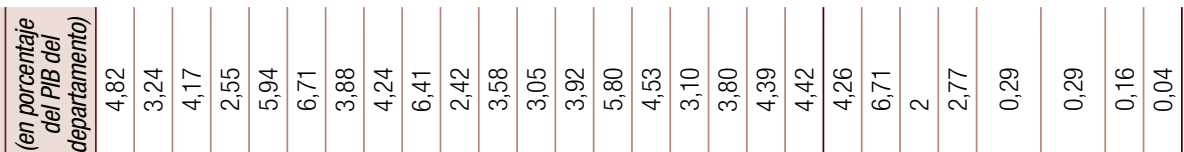

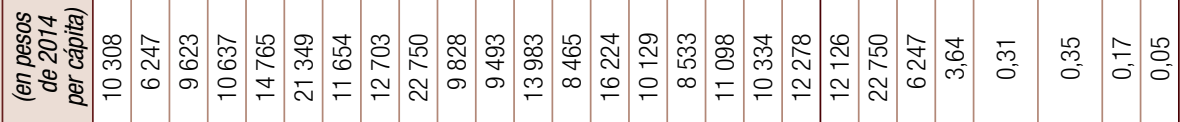

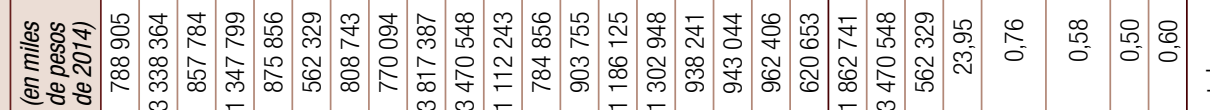

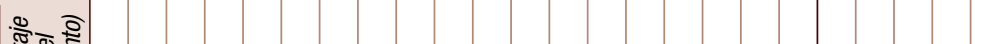

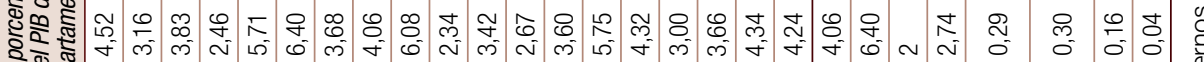

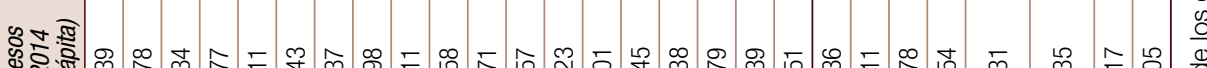

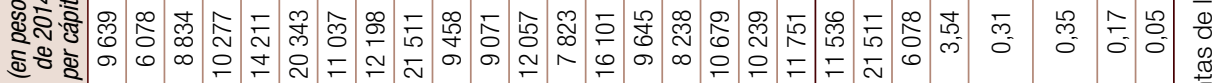

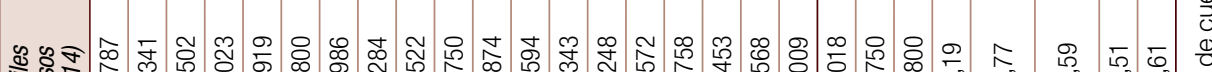

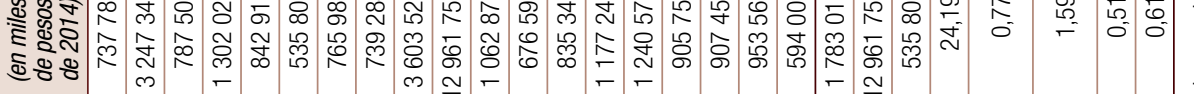

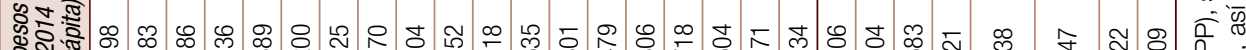

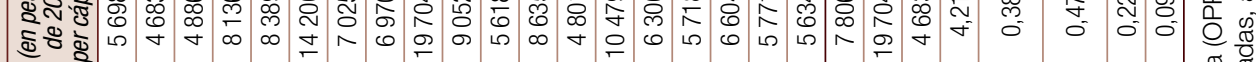

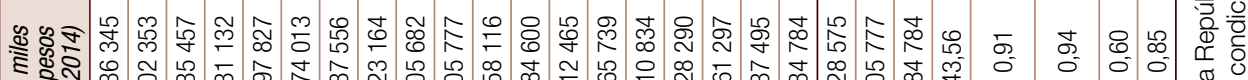

芠

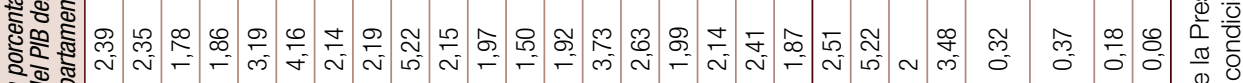

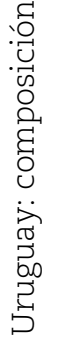
웡 क्षे

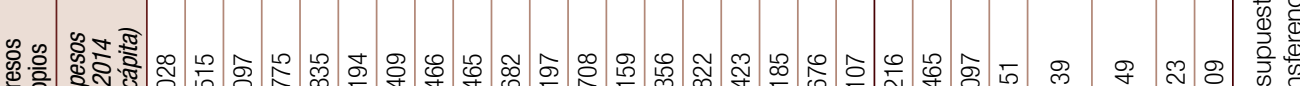

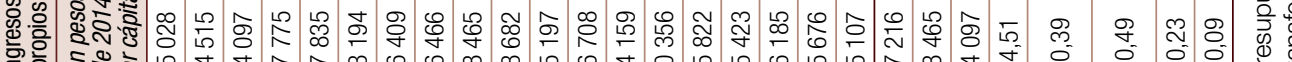

केष ॠ

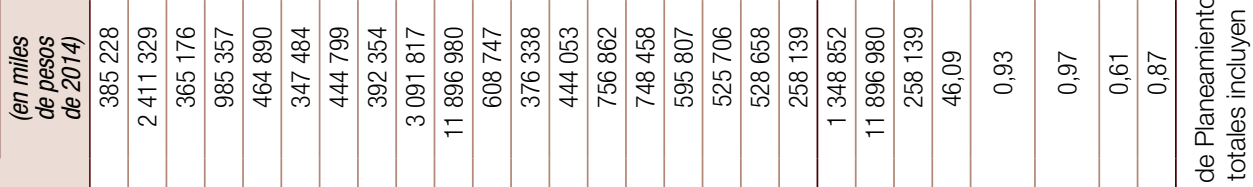


Las medidas estadísticas aportadas en el cuadro 2 indican que las transferencias (condicionadas y no condicionadas) han dado lugar a una reducción del nivel de disparidad de ingresos fiscales entre los gobiernos departamentales. Dentro de este marco, cabe indicar que el menor impacto de las transferencias condicionadas (que reducen el índice Gini en 1 punto porcentual mientras que las no condicionadas lo reducen en 6 puntos porcentuales) se explica por el simple hecho de que este tipo de transferencias son de un volumen muy inferior en relación a las transferencias no condicionadas (véase la penúltima fila del cuadro 2). Esta reducción en el nivel de disparidades de ingresos per cápita entre los gobiernos departamentales también se observa al utilizar otros indicadores de disparidad como la desviación estándar (en logaritmos), coeficiente de variación e índice de Theil. Cabe puntualizar que se observa una variación de la relación máximo/mínimo: la diferencia de ingresos per cápita entre los departamentos con mayores y menores ingresos per cápita se reduce desde 4,5 hasta 3,6 al incorporar las transferencias.

Pese a que existe cierto efecto ecualizador en términos de ingresos de los gobiernos departamentales, la igualación fiscal no forma parte de manera explícita y clara de la normativa que rige la distribución de las transferencias intergubernamentales en el Uruguay. La inexistencia de un régimen normativo adecuado y explícito de transferencias de igualación, basado exclusivamente en criterios técnicos, se debe a varias causas. En primer lugar, el hecho de que ha habido cierta inercia histórica en el ámbito de la negociación política entre el gobierno central y los gobiernos departamentales, la cual no permite avanzar en procesos de mayor autonomía de los diferentes gobiernos departamentales. En este caso, podría revestir importancia el hecho de que el gobierno central muestra ciertas reticencias a la hora de brindar un mayor grado de autonomía a los gobiernos regionales. Cabe citar al respecto el comportamiento inercial de los gobiernos departamentales, que muchas veces obtienen recursos del gobierno central a través de la negociación política, sin incurrir en los costos económicos y políticos que implica realizar un mayor esfuerzo fiscal. En segundo lugar, la existencia de limitaciones técnicas importantes, tanto en el ámbito del gobierno central como - principalmente-en el de los gobiernos departamentales, que se ven reflejadas en la escasez de personal técnico y de bases de datos adecuadas con las cuales construir y actualizar los indicadores técnicos necesarios para diseñar un esquema de transferencias objetivo y ecualizador.

Teniendo en cuenta este contexto, en las dos secciones siguientes se detallan los datos y la metodología empírica que hemos utilizado para explorar la implementación de un nuevo sistema de transferencias intergubernamentales de tipo ecualizador en el Uruguay.

\section{Disparidades fiscales horizontales y efecto ecualizador del actual sistema de transferencias en el Uruguay}

En esta sección se identifican y analizan las disparidades fiscales horizontales existentes entre los gobiernos departamentales del Uruguay. Con respecto a la capacidad de generar ingresos propios, se presentan indicadores de su distribución entre dichos gobiernos, incluidas estimaciones en términos per cápita. Con respecto a los gastos, se incluyen indicadores de disparidades de gastos per cápita entre los gobiernos departamentales.

Al analizar estos indicadores fiscales (véase el cuadro 3), resulta posible detectar disparidades fiscales horizontales importantes al constatar la existencia de grandes diferencias en el nivel de ingresos, transferencias y gastos entre los distintos gobiernos departamentales. Dado que por normativa todos los gobiernos departamentales deben prestar los mismos servicios, las grandes diferencias existentes en términos de gasto total per cápita deberían tener implicancias importantes 
en cuanto a la cantidad y calidad de los servicios prestados (por ejemplo, Maldonado cuenta con un gasto per cápita 3,5 veces superior a Canelones). Con relación a los ingresos totales per cápita también se detectan grandes diferencias (por ejemplo, Maldonado tiene un ingreso per cápita casi 4 veces más elevado que Canelones).

\section{Cuadro 3}

Uruguay: ingresos, transferencias y gastos per cápita por departamento, 2006-2014

(En pesos constantes y medias)

\begin{tabular}{|c|c|c|c|c|c|c|c|c|c|}
\hline Departamento & $\begin{array}{l}\text { Ingresos } \\
\text { propios } \\
\text { per cápita } \\
\text { (1) }\end{array}$ & $\begin{array}{l}\text { Porcentaje } \\
\text { de la media } \\
\text { Uruguay } \\
(2)\end{array}$ & $\begin{array}{l}\text { Transferencias } \\
\text { per cápita } \\
\text { (3) }\end{array}$ & $\begin{array}{l}\text { Porcentaje } \\
\text { de la media } \\
\text { Uruguay } \\
\text { (4) }\end{array}$ & $\begin{array}{c}\text { Ingresos } \\
\text { Totales } \\
\text { per cápita } \\
\text { (5) }\end{array}$ & $\begin{array}{c}\text { Porcentaje } \\
\text { de la media } \\
\text { Uruguay } \\
\text { (6) }\end{array}$ & $\begin{array}{c}\text { Gastos } \\
\text { Totales } \\
\text { per cápita } \\
(7) \\
\end{array}$ & $\begin{array}{c}\text { Porcentaje } \\
\text { de la media } \\
\text { Uruguay } \\
\text { (8) }\end{array}$ & $\begin{array}{l}\text { PIB per cápita } \\
\text { Uruguay=100 }\end{array}$ \\
\hline Artigas & 5028 & 70 & 5280 & 108 & 10308 & 85 & 9781 & 81 & 73 \\
\hline Canelones & 4515 & 63 & 1732 & 35 & 6247 & 52 & 6655 & 55 & 66 \\
\hline Cerro Largo & 4097 & 57 & 5526 & 113 & 9623 & 79 & 9908 & 82 & 78 \\
\hline Colonia & 7775 & 108 & 2862 & 58 & 10637 & 88 & 11064 & 91 & 141 \\
\hline Durazno & 7835 & 109 & 6931 & 141 & 14765 & 122 & 14176 & 117 & 86 \\
\hline Flores & 13194 & 183 & 8155 & 166 & 21349 & 176 & 21657 & 179 & 109 \\
\hline Florida & 6409 & 89 & 5245 & 107 & 11654 & 96 & 11533 & 95 & 103 \\
\hline Lavalleja & 6466 & 90 & 6237 & 127 & 12703 & 105 & 12451 & 103 & 103 \\
\hline Maldonado & 18465 & 256 & 4285 & 87 & 22750 & 188 & 23562 & 195 & 121 \\
\hline Montevideo & 8682 & 120 & 1147 & 23 & 9828 & 81 & 9879 & 82 & 139 \\
\hline Paysandú & 5197 & 72 & 4296 & 87 & 9493 & 78 & 9999 & 83 & 91 \\
\hline Rio Negro & 6708 & 93 & 7275 & 148 & 13983 & 115 & 13694 & 113 & 168 \\
\hline Rivera & 4159 & 58 & 4306 & 88 & 8465 & 70 & 8657 & 72 & 75 \\
\hline Rocha & 10356 & 144 & 5868 & 119 & 16224 & 134 & 14988 & 124 & 95 \\
\hline Salto & 5822 & 81 & 4307 & 88 & 10129 & 84 & 10734 & 89 & 78 \\
\hline San José & 5423 & 75 & 3109 & 63 & 8533 & 70 & 8785 & 73 & 96 \\
\hline Soriano & 6185 & 86 & 4913 & 100 & 11098 & 92 & 11198 & 93 & 103 \\
\hline Tacuarembó & 5676 & 79 & 4657 & 95 & 10334 & 85 & 9668 & 80 & 80 \\
\hline Treinta y Tres & 5107 & 71 & 7171 & 146 & 12278 & 101 & 11622 & 96 & 95 \\
\hline Uruguay & 7216 & 100 & 4911 & 100 & 12126 & 100 & 12106 & 100 & 100 \\
\hline
\end{tabular}

Fuente: Oficina de Planeamiento y Presupuesto de la Presidencia de la República (OPP), sobre la base de rendiciones de cuentas de los gobiernos departamentales.

A efectos de profundizar en el análisis de estas diferencias en el volumen de ingresos totales per cápita, cabe indagar qué ocurre con los ingresos propios y las transferencias. Así, se constata una importante disparidad en cuanto a los ingresos propios per cápita por gobierno departamental: algunos departamentos presentan un nivel casi cinco veces superior a otros (por ejemplo, Maldonado respecto a Cerro Largo). Si a esto se añaden informaciones relativas a las transferencias per cápita realizadas por parte del gobierno central, también se observan diferencias relevantes, aunque de un orden de magnitud inferior a las detectadas para el caso de los ingresos propios. Además, resulta posible constatar que estas transferencias intergubernamentales parecen estar poco relacionadas con el nivel de PIB per cápita. Por ejemplo, aunque Maldonado presenta un nivel de ingresos propios y PIB per cápita claramente superiores a Canelones, recibe unas transferencias en términos per cápita que, a pesar de ser considerablemente inferiores a la media del país, duplican con creces las que percibe Canelones. 
Siguiendo con la misma línea argumental, encontramos departamentos relativamente ricos con niveles de renta similares (Maldonado y Colonia) que ejecutan un monto de recursos muy diferente. Lo mismo ocurre si comparamos departamentos relativamente más pobres, pero con rentas similares (Durazno y San José) o departamentos con niveles de PIB per cápita similares a la media del país (Rocha y Flores) que presentan niveles de ingresos o de gastos totales muy distintos, así como niveles de transferencias muy diferentes.

En conclusión, nos encontramos con una heterogeneidad fiscal muy acentuada entre los niveles de gasto, ingresos propios y transferencias intergubernamentales que no parecen guardar relación alguna con el nivel de PIB per cápita de los departamentos y, por ende, con el distinto potencial recaudador de los gobiernos departamentales.

Por último, presentamos indicadores de disparidades fiscales para cada uno de los gobiernos departamentales y su relación con el nivel de transferencias intergubernamentales no condicionadas, pues son esas transferencias las que en teoría deberían tener un mayor efecto ecualizador. Con este objeto, para cada gobierno departamental i $\left(G D_{j}\right)$ se calcula el siguiente indicador de disparidad fiscal:

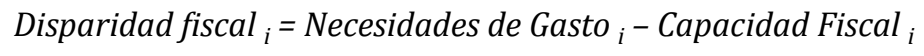

En este sentido, y debido a falta de información más adecuada, consideramos como indicador de necesidades de gasto el promedio nacional de gasto per cápita efectivamente ejecutado por los gobiernos departamentales durante el período 2006-2014. Por su parte, los ingresos propios per cápita recaudados durante dicho período por cada uno de los gobiernos departamentales servirían de indicador de capacidad fiscal.

El análisis del cuadro 4 nos permite constatar una tendencia claramente creciente, tanto en el nivel de necesidades de gasto como en el de capacidad fiscal. A su vez, se observa un incremento aún más importante en el nivel de disparidades fiscales per cápita durante el período objeto de análisis ${ }^{7}$. Además, se observa un marcado aumento del nivel de transferencias no condicionadas expresadas en términos per cápita (con una tasa de crecimiento del $61 \%$ en el mismo período). Este resultado da a entender que, en términos dinámicos, parece no existir un efecto ecualizador de las transferencias no condicionadas en el Uruguay. Vale decir, las transferencias no habrían reducido, en términos agregados, el nivel de disparidad fiscal de los gobiernos departamentales a lo largo del período analizado. De hecho, observamos que la tasa de aumento de las disparidades fiscales es mayor que la de las transferencias intergubernamentales. Este resultado podría estar reflejando cierto comportamiento de indisciplina fiscal por parte de los gobiernos departamentales. Más específicamente, al recibir recursos por medio de transferencias intergubernamentales sin incurrir en los costos económicos o políticos que lleva aparejada la recaudación de recursos propios, pareciera que estos gobiernos departamentales exhiben un comportamiento displicente en cuanto a la ejecución de recursos.

\footnotetext{
7 Por ejemplo, la tasa de variación simple del nivel de disparidades fiscales es del 119\% para el período 2006-2014.
} 
Cuadro 4

Uruguay: necesidades de gasto, capacidad fiscal, disparidad fiscal

y transferencias no condicionadas, 2006-2014

(A precios constantes de 2014)

\begin{tabular}{lcccc}
\hline & $\begin{array}{c}\text { Necesidades de } \\
\text { gasto per cápita }\end{array}$ & $\begin{array}{c}\text { Capacidad fiscal } \\
\text { per cápita }\end{array}$ & $\begin{array}{c}\text { Disparidad fiscal } \\
\text { per cápita }\end{array}$ & $\begin{array}{c}\text { Transferencias no } \\
\text { condicionadas per cápita }\end{array}$ \\
\hline 2006 & 9978 & 6713 & 3265 & 3475 \\
\hline 2007 & 10615 & 6868 & 3747 & 3537 \\
\hline 2008 & 11396 & 7214 & 4182 & 3824 \\
\hline 2009 & 12004 & 6831 & 5173 & 4096 \\
\hline 2010 & 11389 & 6975 & 4414 & 4128 \\
\hline 2012 & 12076 & 7254 & 4822 & 4485 \\
\hline 2013 & 12442 & 7418 & 5024 & 4632 \\
\hline 2014 & 13942 & 7717 & 6225 & 5117 \\
\hline
\end{tabular}

Fuente: Oficina de Planeamiento y Presupuesto de la Presidencia de la República (OPP), sobre la base de rendiciones de cuentas de los gobiernos departamentales.

En el cuadro 5 se presenta información acerca de las anteriores variables, pero desagregadas por departamento. Este cuadro nos permite constatar un incremento generalizado en el nivel de disparidades fiscales medida en términos per cápita, acompañado de un aumento generalizado de las transferencias no condicionadas per cápita. No se observa un efecto ecualizador muy destacable de las transferencias no condicionadas. Si bien se reducen los índices de disparidad entre los ingresos totales de los diferentes gobiernos departamentales, estos disminuyen en una proporción menor a un tercio, lo cual se puede considerar como un efecto leve, especialmente si se lo compara con el hecho que, tal como señala Martínez-Vázquez (2015), los países de la OCDE logran disminuir las disparidades fiscales en más de dos tercios con sus transferencias de igualación.

\section{Cuadro 5}

Uruguay: necesidades de gasto y capacidad fiscal, por departamento y años seleccionados (A precios constantes de 2014)

\begin{tabular}{|c|c|c|c|c|c|c|c|c|c|}
\hline \multirow[t]{2}{*}{ Departamento } & \multicolumn{3}{|c|}{ Necesidades de gasto per cápita } & \multicolumn{3}{|c|}{ Capacidad fiscal per cápita } & \multicolumn{3}{|c|}{$\begin{array}{l}\text { Capacidad fiscal incluyendo } \\
\text { transferencias no } \\
\text { condicionadas per cápita }\end{array}$} \\
\hline & 2006 & 2009 & 2014 & 2006 & 2009 & 2014 & 2006 & 2009 & 2014 \\
\hline Artigas & 9978 & 12004 & 15111 & 4735 & 5024 & 5134 & 8114 & 9178 & 11494 \\
\hline Canelones & 9978 & 12004 & 15111 & 4411 & 3971 & 5072 & 5642 & 5577 & 7034 \\
\hline Cerro Largo & 9978 & 12004 & 15111 & 3990 & 3505 & 4670 & 7866 & 7439 & 10842 \\
\hline Colonia & 9978 & 12004 & 15111 & 5210 & 7364 & 9892 & 7259 & 9634 & 13076 \\
\hline Durazno & 9978 & 12004 & 15111 & 7328 & 7125 & 7970 & 12297 & 13261 & 15720 \\
\hline Flores & 9978 & 12004 & 15111 & 11658 & 11361 & 15665 & 17780 & 17942 & 24699 \\
\hline Florida & 9978 & 12004 & 15111 & 6085 & 6411 & 8068 & 10421 & 10656 & 14151 \\
\hline Lavalleja & 9978 & 12004 & 15111 & 6560 & 6713 & 6521 & 11030 & 11169 & 14259 \\
\hline Maldonado & 9978 & 12004 & 15111 & 18049 & 18146 & 18904 & 21022 & 21647 & 22622 \\
\hline Montevideo & 9978 & 12004 & 15111 & 8491 & 8993 & 9678 & 9354 & 9733 & 10656 \\
\hline Paysandú & 9978 & 12004 & 15111 & 5164 & 5072 & 5248 & 8579 & 8424 & 10153 \\
\hline Rio Negro & 9978 & 12004 & 15111 & 6444 & 6279 & 7027 & 10903 & 11746 & 14651 \\
\hline Rivera & 9978 & 12004 & 15111 & 3634 & 3917 & 4514 & 6776 & 7315 & 9230 \\
\hline
\end{tabular}




\begin{tabular}{|c|c|c|c|c|c|c|c|c|c|}
\hline \multirow[t]{2}{*}{ Departamento } & \multicolumn{3}{|c|}{ Necesidades de gasto per cápita } & \multicolumn{3}{|c|}{ Capacidad fiscal per cápita } & \multicolumn{3}{|c|}{$\begin{array}{l}\text { Capacidad fiscal incluyendo } \\
\text { transferencias no } \\
\text { condicionadas per cápita }\end{array}$} \\
\hline & 2006 & 2009 & 2014 & 2006 & 2009 & 2014 & 2006 & 2009 & 2014 \\
\hline Rocha & 9978 & 12004 & 15111 & 7752 & 9258 & 11093 & 10929 & 15376 & 19242 \\
\hline Salto & 9978 & 12004 & 15111 & 5759 & 5584 & 5921 & 8697 & 8944 & 10507 \\
\hline San José & 9978 & 12004 & 15111 & 5538 & 5446 & 5606 & 8077 & 8158 & 9243 \\
\hline Soriano & 9978 & 12004 & 15111 & 5860 & 5516 & 6951 & 9810 & 10429 & 12574 \\
\hline Tacuarembó & 9978 & 12004 & 15111 & 5492 & 4787 & 8139 & 9086 & 9126 & 13907 \\
\hline Treinta y Tres & 9978 & 12004 & 15111 & 5380 & 5324 & 4998 & 9921 & 11866 & 13261 \\
\hline Media & 9978 & 12004 & 15111 & 6713 & 6831 & 7951 & 10188 & 10927 & 13543 \\
\hline Máximo & 9978 & 12004 & 15111 & 18049 & 18146 & 18904 & 21022 & 21647 & 24699 \\
\hline Mínimo & 9978 & 12004 & 15111 & 3634 & 3505 & 4514 & 5642 & 5577 & 7034 \\
\hline Máximo/Mínimo & 1 & 1 & 1 & 5,0 & 5,2 & 4,2 & 3,7 & 3,9 & 3,5 \\
\hline $\begin{array}{l}\text { Desviación estándar } \\
\text { (en logs) }\end{array}$ & 0 & 0 & 0 & 0,373 & 0,396 & 0,403 & 0,309 & 0,323 & 0,311 \\
\hline Coeficiente de variación & 0 & 0 & 0 & 0,49 & 0,495 & 0,482 & 0,361 & 0,356 & 0,334 \\
\hline Índice de Gini & 0 & 0 & 0 & 0,213 & 0,227 & 0,234 & 0,171 & 0,179 & 0,172 \\
\hline Índice de Theil & 0 & 0 & 0 & 0,09 & 0,095 & 0,094 & 0,049 & 0,055 & 0,049 \\
\hline
\end{tabular}

Fuente: Oficina de Planeamiento y Presupuesto de la Presidencia de la República (OPP), sobre la base de rendiciones de cuentas de los gobiernos departamentales.

A su vez, para el caso del Uruguay también podemos señalar que a pesar de observarse una tendencia creciente en el monto de transferencias intergubernamentales expresadas en términos per cápita, no se ha producido un aumento de su rol ecualizador. Por el contrario, durante el período objeto de análisis observamos una leve desmejora del rol ecualizador de las transferencias intergubernamentales.

\section{Opciones de reforma y proyecciones}

Un régimen de transferencias ecualizadoras busca que todos los gobiernos subnacionales puedan proveer servicios de calidad similar con un esfuerzo tributario equivalente (Martínez-Vázquez y Sepúlveda, 2012). A este respecto, se pueden distinguir distintas opciones para diseñar un sistema de transferencias ecualizadoras:

a) La primera opción consiste en igualar las necesidades de gasto de los gobiernos subnacionales sin tomar en cuenta sus diferentes capacidades para recaudar ingresos propios. Esta opción se aplica en países en los que los gobiernos subnacionales no cuentan con fuentes de ingresos propios.

b) La segunda opción consiste en igualar la capacidad de generar ingresos propios por parte de los gobiernos subnacionales. Este enfoque busca asegurar que, con el mismo nivel de esfuerzo tributario, todas las unidades subnacionales obtengan los mismos ingresos. Dicha opción resulta óptima cuando el costo de provisión de los diferentes servicios públicos locales es muy similar en todo el territorio nacional.

c) La tercera opción consiste en igualar la diferencia entre la capacidad de generar ingresos propios y las necesidades de gasto de los gobiernos subnacionales. Aquí se toman en cuenta tanto los ingresos potenciales como las necesidades de gastos de los diferentes gobiernos subnacionales (ejemplos: Australia, Dinamarca, China y Etiopía). 
En este trabajo nos basamos en la tercera opción, consistente en igualar la diferencia entre la capacidad de generar ingresos propios y las necesidades de gasto de los gobiernos regionales. El conjunto de disparidades fiscales de los gobiernos departamentales del Uruguay provee la información necesaria para distribuir el hipotético fondo de transferencias de igualación ${ }^{8}$.

Queda por definir el criterio de distribución de las transferencias entre los gobiernos departamentales. Un punto de partida consiste en establecer que los recursos solo podrán beneficiar a los gobiernos departamentales cuya disparidad fiscal sea positiva. En nuestro caso, este criterio se consideró adecuado porque permite mejorar la capacidad ecualizadora de las transferencias, al excluir del grupo de beneficiarios a aquellos gobiernos departamentales que cuentan con recursos fiscales suficientes como para cubrir sus necesidades de gasto. Con relación a la capacidad fiscal (ingresos departamentales propios) se consideran de forma desagregada las tres principales fuentes de ingresos de los gobiernos departamentales: contribución inmobiliaria rural, contribución inmobiliaria urbana y suburbana, y patente de rodados. El resto de los ingresos de los gobiernos departamentales se agrupan en el rubro "otros"9.

La base imponible de la patente de rodados se estimó a partir de datos de 2014 referentes a la emisión de deuda de patente de rodados ${ }^{10}$, considerando una alícuota media del 4,5. Se trata este último del porcentaje que se aplica al valor de mercado de los vehículos (base imponible) a fin de obtener el monto a pagar por concepto de patente de rodados (emisión de deuda). Por su parte, la base impositiva para el cálculo del impuesto a la propiedad urbana y rural en 2014 se refiere al agregado del valor sujeto a impuestos de los inmuebles urbanos, suburbanos y rurales, provenientes de la Dirección Nacional de Catastro (DNC) ${ }^{11}$. Por último, la diversidad de tasas y precios del rubro "otros" impide obtener una medida directa de la base imponible, por lo cual se utilizó como variable representativa (proxy) el PIB de cada departamento.

Al estimar los ingresos potenciales de los diferentes gobiernos departamentales, se aplica a la base imponible correspondiente la tasa impositiva promedio del país, suponiendo que esta tasa se corresponde con el esfuerzo fiscal requerido para cada tributo. En base a esta información referente a ingresos potenciales de las principales fuentes de ingresos propios de los gobiernos departamentales del Uruguay, se procedió a utilizar la metodología del sistema impositivo representativo de estos gobiernos regionales. Los datos correspondientes a bases imponibles por tipo de tributo y tasas impositivas efectivas se detallan en los cuadros 6 y 7 respectivamente.

8 Véase el anexo A3 para apreciar con mayor detalle la metodología de ecualización fiscal utilizada.

9 El rubro "otros" se compone de un conjunto amplio de tasas de menor cuantía. Entre estos destacan las tasas bromatológicas, administrativas y de servicios municipales.

${ }^{10}$ La emisión de deuda de la patente de rodados se calcula a partir de la base imponible - compuesta por los vehículos según año y modelo - y una alícuota diferencial. Dado que contamos con información de emisión de deuda proveniente del Sistema Unico de Cobro de Ingresos Vehiculares (SUCIVE [en línea] -https://www.sucive.gub.uy/) y suponemos una alícuota media del $4,5 \%$, procedemos a estimar la correspondiente base imponible.

11 Véase en línea http://catastro.mef.gub.uy/. 


\section{Cuadro 6}

Uruguay: bases imponibles por tipo de tributo, 2014

(En términos per cápita)

\begin{tabular}{|c|c|c|c|c|}
\hline \multirow[b]{2}{*}{ Departamento } & \multicolumn{4}{|c|}{ Base imponible } \\
\hline & $\begin{array}{l}\text { Contribución } \\
\text { inmobiliaria rural }\end{array}$ & $\begin{array}{c}\text { Contribución } \\
\text { inmobiliaria urbana } \\
\text { y suburbana }\end{array}$ & $\begin{array}{l}\text { Patente } \\
\text { de rodados }\end{array}$ & $\begin{array}{l}\text { PIB (variable representativa (proxy) } \\
\text { para el resto de los tributos para lo } \\
\text { que no se dispone de información) }\end{array}$ \\
\hline Artigas & 147719 & 101196 & 35417 & 271696 \\
\hline Canelones & 21671 & 152215 & 33276 & 222471 \\
\hline Cerro Largo & 144388 & 119710 & 40659 & 274954 \\
\hline Colonia & 87191 & 234410 & 138602 & 490967 \\
\hline Durazno & 231476 & 92526 & 77963 & 318157 \\
\hline Flores & 294025 & 175647 & 237147 & 396049 \\
\hline Florida & 202656 & 33531 & 80543 & 369517 \\
\hline Lavalleja & 164964 & 145774 & 49848 & 377115 \\
\hline Maldonado & 23437 & 722437 & 130833 & 409574 \\
\hline Montevideo & 4620 & 344286 & 41212 & 487462 \\
\hline Paysandú & 135909 & 140369 & 50705 & 329880 \\
\hline Río Negro & 240600 & 129280 & 58499 & 616314 \\
\hline Rivera & 83783 & 117460 & 39132 & 270444 \\
\hline Rocha & 120669 & 154112 & 47757 & 342635 \\
\hline Salto & 105601 & 154265 & 46721 & 282289 \\
\hline San José & 93914 & 37617 & 76682 & 343711 \\
\hline Soriano & 188106 & 167995 & 60388 & 393306 \\
\hline Tacuarembó & 155466 & 123548 & 56237 & 280089 \\
\hline Treinta y Tres & 150203 & 132747 & 53361 & 333809 \\
\hline Promedio del país & 61765 & 250199 & 54258 & 386826 \\
\hline
\end{tabular}

Fuente: Para contribución inmobiliaria rural, urbana y suburbana: Dirección Nacional de Catastro (DNC); para patente de rodados: Sistema Único de Sistema Único de Cobro de Ingresos Vehiculares (SUCIVE); para el PIB: Banco Central del Uruguay (BCU), Instituto de Economía (IECON) y Oficina de Planeamiento y Presupuesto de Presidencia de la República (OPP).

Cuadro 7

Uruguay: tasas impositivas efectivas estimadas, según tipo de tributo, 2014 (En porcentajes)

\begin{tabular}{lc}
\hline & Tasa impositiva efectiva \\
\hline Contribución inmobiliaria rural & 0,8 \\
\hline Contribución inmobiliaria urbana y suburbana & 0,7 \\
\hline Patente de rodados & 3,6 \\
\hline Otros & 1,1 \\
\hline
\end{tabular}

Fuente: Elaboración propia.

Dado que los gobiernos departamentales en el Uruguay cumplen funciones de tipo municipal, no resulta adecuado utilizar la distribución de la población departamental por edades para estimar sus necesidades de gasto. A su vez, tampoco se cuenta con información exhaustiva y homogénea sobre los niveles de gastos por funciones de los distintos gobiernos departamentales. En este sentido, se procedió a estimar las necesidades de gasto de dichos gobiernos a través de la norma del gasto per cápita a nivel nacional durante el período 2006-2014. Además, se consideró que el costo per cápita de proveer estos servicios varía entre los distintos departamentos en función de su densidad poblacional. A este respecto, se consideró un costo menor del servicio cuanto mayor densidad poblacional existiese en el departamento (habitantes por kilómetro cuadrado). 


\section{Ejercicios de ecualización}

Cabe destacar que la realidad demográfica de los distintos departamentos del Uruguay determina que existan densidades poblacionales bajas (la mayoría de los departamentos tienen menos de 20 habitantes por $\mathrm{km}^{2}$ ), junto con una notable dispersión de los residentes en poblaciones de tamaño pequeño. Dado que los servicios se encuentran en puntos discretos del espacio, los costos de provisión per cápita ante una demanda potencial escasa y dispersa podrían ser mayores en dichos departamentos que en aquellos con espacios urbanos o semiurbanos muy desarrollados. La existencia de economías de aglomeración podría incidir en los costos de provisión de bienes y servicios, pues supondrían una disminución del costo por usuario a medida que aumenta la densidad poblacional. En otras palabras, una mayor dispersión de la población en el territorio reduce el aprovechamiento de las economías de densidad asociadas a la provisión del servicio, incrementando de forma ineficiente los costos (Carruthers y Ulfarsson, 2003; Hortas-Rico y Solé-Ollé, 2010). Una mayor densidad poblacional reduciría los costos de producción de estos servicios, ya sea porque daría lugar a una reducción en el número de centros necesarios para prestar un determinado nivel de servicio, porque disminuirían los costos de transporte asociados al mismo, o porque se reduciría la distancia media a la que están situados los potenciales usuarios respecto al centro de prestación del servicio. Teniendo en cuenta estos supuestos, se procedió a recalcular las necesidades de gastos locales en base a la densidad poblacional de los diferentes departamentos. Se utilizó la inversa del logaritmo de la densidad, en el entendido de que a medida que aumenta la densidad de población los costos disminuyen, pero menos que proporcionalmente. Por otra parte, se normalizaron los valores en el rango comprendido entre 1 y 2. Aplicando este coeficiente de ajuste, se verifica que al departamento con mayor densidad de población -Montevideo- le corresponde un coeficiente de ajuste igual a 1 y, por lo tanto, es utilizado como referencia ya que sus necesidades de gasto no se modifican, mientras que el resto de departamentos incrementan sus necesidades de gasto debido a su menor densidad de población (véase el cuadro 8).

Cuadro 8

Uruguay: densidad de población por departamentos

\begin{tabular}{lcc}
\hline Departamento & $\begin{array}{c}\text { Densidad } \\
\left.\text { (habitante/ } \mathrm{km}^{2}\right)\end{array}$ & Coeficiente corrector \\
\hline Artigas & 6,30 & 1,843 \\
\hline Canelones & 116,80 & 1,170 \\
\hline Cerro Largo & 6,53 & 1,833 \\
\hline Colonia & 20,64 & 1,417 \\
\hline Durazno & 4,86 & 2,000 \\
\hline Flores & 5,12 & 1,997 \\
\hline Florida & 6,67 & 1,822 \\
\hline Lavalleja & 6,06 & 1,879 \\
\hline Maldonado & 34,54 & 1,317 \\
\hline Montevideo & 2554,50 & 1,000 \\
\hline Paysandú & 8,37 & 1,703 \\
\hline Rio Negro & 5,87 & 1,881 \\
\hline Rivera & 11,43 & 1,172 \\
\hline Rocha & 6,93 & 1,800 \\
\hline Salto & 9,20 & 1,670 \\
\hline San José & 21,87 & 1,403 \\
\hline Soriano & 9,46 & 1,654 \\
\hline Tacuarembó & 5,83 & 1,882 \\
\hline Treinta y Tres & 5,45 & 1,981 \\
\hline Fuente: Eaba & & \\
\hline
\end{tabular}

Fuente: Elaboración propia, sobre la base de datos del Instituto Nacional de Estadística (INE) del Uruguay. 
La incorporación de dicha información al ejercicio de ecualización permite considerar distintas necesidades de gasto per cápita por departamento, pudiéndose así obtener distintos niveles de brechas fiscales (véase el cuadro 9).

\section{Cuadro 9}

Uruguay: estimación de la brecha fiscal por departamento corregida por densidad poblacional, 2014

\begin{tabular}{|c|c|c|c|c|c|c|}
\hline \multirow{4}{*}{ Departamento } & \multirow{2}{*}{\multicolumn{2}{|c|}{$\begin{array}{c}\text { Necesidades de gasto } \\
\text { Gasto per cápita }\end{array}$}} & \multicolumn{3}{|c|}{ Ingresos } & \multirow{4}{*}{$\begin{array}{c}\text { Brecha } \\
\text { (2) - (4) - (5) }\end{array}$} \\
\hline & & & \multicolumn{2}{|c|}{ Departamentales } & \multirow{3}{*}{$\begin{array}{c}\text { De origen nacionald } \\
\text { (5) }\end{array}$} & \\
\hline & Actual & Norma $^{\mathrm{a}}$ & Actual $^{b}$ & Norma $^{\mathrm{c}}$ & & \\
\hline & (1) & (2) & (3) & (4) & & \\
\hline Artigas & 9764 & 19408 & 5026 & 5298 & 667 & 13443 \\
\hline Canelones & 6657 & 12319 & 4525 & 4483 & 171 & 7665 \\
\hline Cerro Largo & 9912 & 19308 & 4098 & 5777 & 789 & 12742 \\
\hline Colonia & 11088 & 14918 & 7795 & 11410 & 362 & 3146 \\
\hline Durazno & 14166 & 21061 & 7834 & 7694 & 555 & 12811 \\
\hline Flores & 21678 & 21031 & 13205 & 14627 & 1008 & 5396 \\
\hline Florida & 11529 & 19185 & 6408 & 7609 & 616 & 10959 \\
\hline Lavalleja & 12438 & 19787 & 6466 & 7155 & 508 & 12125 \\
\hline Maldonado & 23604 & 13868 & 18472 & 13630 & 1278 & -1039 \\
\hline Montevideo & 9882 & 10530 & 8682 & 8252 & 371 & 1907 \\
\hline Paysandú & 10002 & 17936 & 5197 & 6618 & 421 & 10896 \\
\hline Rio Negro & 13705 & 19987 & 6709 & 10247 & 1930 & 7810 \\
\hline Rivera & 8661 & 16671 & 4160 & 5147 & 641 & 10883 \\
\hline Rocha & 15004 & 18958 & 10359 & 6637 & 122 & 12199 \\
\hline Salto & 10745 & 17586 & 5822 & 5918 & 485 & 11184 \\
\hline San José & 8806 & 14792 & 5422 & 6665 & 296 & 7831 \\
\hline Soriano & 11187 & 17415 & 6183 & 7769 & 419 & 9228 \\
\hline Tacuarembó & 9668 & 20047 & 5677 & 6421 & 95 & 13531 \\
\hline Treinta y Tres & 11622 & 20743 & 5107 & 6880 & 527 & 13336 \\
\hline Total & 10530 & 10530 & 7541 & 7541 & 446 & 2544 \\
\hline
\end{tabular}

Fuente: Elaboración propia, sobre la base de Oficina de Planeamiento y Presupuesto de la Presidencia de la República (OPP), "Clasificador de ingresos y gastos" [en línea] https://otu.opp.gub.uy/sites/default/files/finanzas/clasificador_ingresos_ egresos.pdf.

a Se asume como norma el promedio per cápita nacional 2006-2014 a pesos uruguayos de 2014, y se ajusta por densidad de población.

b Excluye las transferencias ecualizadoras, y los ingresos de origen nacional, inciso 2.2 del documento "Clasificador de ingresos y gastos" (recursos con destino específico).

c Calculado en base al potencial de ingresos por patentes, contribución inmobiliaria - rural, urbana y suburbana- y "otros" con la tasa efectiva promedio nacional correspondiente.

d Se refiere a los ingresos de origen nacional, incisos 2.1 y 2.3 del documento "Clasificador de ingresos y gastos" (recursos establecidos por disposición constitucional y recursos establecidos por otras disposiciones).

Con arreglo a la metodología aquí utilizada, unos ocho gobiernos departamentales recibirían un monto de transferencias mayor al que reciben actualmente. Ellos son: Canelones, Rivera, Tacuarembó, Artigas, Salto, Paysandú, San José y Cerro Largo. En el otro extremo, los gobiernos departamentales que verían reducido el monto de transferencias son Montevideo, Florida, Lavalleja, Rocha, Soriano, Durazno, Treinta y Tres, Río Negro, Colonia, Flores y Maldonado. Estos tres últimos son los que experimentarían la mayor reducción en el monto de las transferencias recibidas, pues se trata de departamentos con una capacidad fiscal relativamente alta; entre ellos se destaca Maldonado, que logra cubrir la totalidad de sus necesidades de gasto sin recurrir a las transferencias (véase la última columna del cuadro 10). 


\section{Cuadro 10}

Uruguay: distribución de transferencias intergubernamentales en función de las brechas fiscales, corregidas por densidad de población, 2014

\begin{tabular}{|c|c|c|c|c|c|c|c|}
\hline \multirow{2}{*}{ Departamento } & \multirow{2}{*}{$\begin{array}{c}\text { Índice de } \\
\text { brecha } \\
\text { a }\end{array}$} & \multirow{2}{*}{$\begin{array}{c}\begin{array}{c}\text { Ponderador } \\
\text { de población }\end{array} \\
\text { b }\end{array}$} & \multirow{2}{*}{$\begin{array}{c}\text { Coeficiente de } \\
\text { Distribución } \\
\text { c }=a^{*} b\end{array}$} & $\begin{array}{l}\text { Distribución } \\
\text { ecualizadora }\end{array}$ & $\begin{array}{c}\text { Distribución } \\
\text { actual }\end{array}$ & \multicolumn{2}{|l|}{ Cambio } \\
\hline & & & & \multicolumn{2}{|c|}{ (en millones de pesos) } & (en millones de pesos) & (porcentaje) \\
\hline Artigas & 5,28 & 0,02 & 0,12 & 416 & 353 & 63,14 & 18 \\
\hline Canelones & 3,01 & 0,16 & 0,47 & 1.648 & 836 & 811,88 & 97 \\
\hline Cerro Largo & 5,01 & 0,03 & 0,13 & 458 & 422 & 35,85 & 8 \\
\hline Colonia & 1,24 & 0,04 & 0,05 & 160 & 317 & $-156,18$ & -49 \\
\hline Durazno & 5,04 & 0,02 & 0,09 & 307 & 378 & $-71,25$ & -19 \\
\hline Flores & 2,12 & 0,01 & 0,02 & 57 & 188 & $-131,02$ & -70 \\
\hline Florida & 4,31 & 0,02 & 0,09 & 307 & 321 & $-14,25$ & -4 \\
\hline Lavalleja & 4,77 & 0,02 & 0,09 & 297 & 347 & $-50,07$ & -14 \\
\hline Maldonado & 0,00 & 0,05 & - & - & 512 & $-511,70$ & -100 \\
\hline Montevideo & 0,75 & 0,40 & 0,30 & 1054 & 1065 & $-10,29$ & -1 \\
\hline Paysandú & 4,28 & 0,03 & 0,15 & 515 & 454 & 60,89 & 13 \\
\hline Río Negro & 3,07 & 0,02 & 0,05 & 177 & 300 & $-123,50$ & -41 \\
\hline Rivera & 4,28 & 0,03 & 0,13 & 469 & 391 & 77,47 & 20 \\
\hline Rocha & 4,80 & 0,02 & 0,10 & 360 & 420 & $-60,77$ & -14 \\
\hline Salto & 4,40 & 0,04 & 0,17 & 580 & 492 & 88,02 & 18 \\
\hline San José & 3,08 & 0,03 & 0,10 & 347 & 310 & 37,30 & 12 \\
\hline Soriano & 3,63 & 0,03 & 0,09 & 317 & 382 & $-65,13$ & -17 \\
\hline Tacuarembó & 5,32 & 0,03 & 0,15 & 508 & 425 & 83,51 & 20 \\
\hline Treinta y Tres & 5,24 & 0,01 & 0,08 & 272 & 336 & $-63,87$ & -19 \\
\hline
\end{tabular}

Fuente: Elaboración propia.

Por último, se realiza el mismo ejercicio de ecualización considerando un incremento del volumen de transferencias no condicionadas del 10\% ( $\triangle T N C=10 \%)$ y del $20 \%(\triangle T N C=20 \%)$, respectivamente (véase el anexo 4). El incremento gradual del volumen de transferencias no condicionadas presenta dos ventajas. En primer lugar, resuelve el problema de caja - al menos en el corto plazo - de algunos gobiernos departamentales que, al implementarse el nuevo sistema, pasarían a percibir un monto menor de transferencias. Con un incremento del 10\% del monto de transferencias no condicionadas, los departamentos de Florida y Montevideo pasan a percibir un monto mayor que las actuales transferencias, en un 5\% y $9 \%$ respectivamente. Si el incremento fuera del 20\%, tres gobiernos departamentales - Lavalleja, Rocha y Soriano - pasarían a recibir un monto mayor de transferencias respecto al escenario de ecualización sin incremento de transferencias. En segundo lugar, si se aumenta el volumen de transferencias no condicionadas, es posible avanzar hacia un mayor nivel de homogeneidad fiscal. Con un incremento del monto de entre un $10 \%$ y un $20 \%$, la reducción de la disparidad fiscal sería del 30\% y el 32\%, respectivamente (véase el cuadro 11).

\section{Cuadro 11}

Uruguay: disparidades fiscales horizontales

\begin{tabular}{lcccc}
\hline \multirow{2}{*}{ Medidas de desigualdad } & Preecualización & \multicolumn{3}{c}{ Posecualización } \\
\cline { 3 - 5 } & & $\Delta T N C=0^{\text {a }}$ & $\Delta T N C=10 \%$ & $\Delta T N C=20 \%$ \\
\hline Coeficiente de variación & 0,34763 & 0,25057 & 0,23926 & 0,22939 \\
\hline Desviación estándar (en logaritmos) & 0,31423 & 0,22548 & 0,21892 & 0,21343 \\
\hline Índice de Gini & 0,17386 & 0,12434 & 0,12089 & 0,1178 \\
\hline Coeficiente de Theil & 0,05204 & 0,02731 & 0,02521 & 0,02346 \\
\hline Máximo/Mínimo & 3,64037 & 2,53571 & 2,43888 & 2,34916 \\
\hline
\end{tabular}

Fuente: Elaboración propia.

a TNC: transferencias no condicionadas. 


\section{Conclusiones}

En el presente artículo se ha analizado el rol ecualizador de las transferencias intergubernamentales a partir de un análisis empírico aplicado a un grupo de regiones del Uruguay durante el período 2006-2014. Más específicamente, se han realizado dos tipos de análisis. En primer lugar, se evaluó el impacto ecualizador del sistema de transferenciales intergubernamentales actualmente vigente en el Uruguay. En segundo lugar, se discutieron los efectos de la implementación de un nuevo sistema de transferencias de tipo ecualizador en ese país. Esta propuesta, basada en criterios objetivos ligados al valor de determinadas variables, permite reducir claramente el nivel de disparidades fiscales horizontales. A este respecto, las transferencias provenientes del gobierno central cumplen un papel más importante como igualitarias o ecualizadoras.

Cabe destacar que la propuesta que aquí se formula da como resultado un mayor monto de transferencias en términos per cápita para cierto número de departamentos, lo que ciertamente podría no coadyuvar al objetivo de un mayor equilibrio territorial de la actividad económica. A pesar de ello, cabe insistir en el hecho de que el monto de los recursos descentralizados en manos de los gobiernos departamentales continúa siendo muy bajo en el Uruguay (del orden del 10\% del gasto público) y que, además, dichos recursos se destinan a cubrir la prestación de unos servicios públicos locales básicos y muy concretos, para los que se debería esperar una cierta homogenización en su calidad en el territorio nacional. Así pues, si se quisieran llevar a cabo políticas destinadas a reducir los desequilibrios territoriales de la actividad económica, probablemente sería más eficaz diseñar, desde el gobierno central, unos instrumentos más específicos y potentes para obtener una mayor cohesión territorial. Por ejemplo, se podrían utilizar con dicho fin programas de inversión en infraestructuras de transporte y comunicaciones, así como estrategias para incentivar la inversión empresarial en determinadas áreas o regiones.

Como ya se indicó, el diseño de un sistema de financiación de los gobiernos departamentales debería centrarse en el debate sobre unos criterios técnicos como los que aquí se proponen, que no han de estar sometidos a la incertidumbre del resultado que produzca la negociación política entre los gobiernos departamentales y las autoridades del gobierno central. En este marco, la reforma más importante a acometer, que permitiría fortalecer la tributación de los gobiernos departamentales estimulando su esfuerzo fiscal, consistiría en definir unas reglas claras, objetivas y simples relativas al sistema de transferencias. Dichas reglas deberían establecerse por un período temporal lo suficientemente amplio como para no verse sujetas periódicamente a cambios políticos. Por otra parte, resulta de suma importancia contar con unos pocos objetivos de política económica claramente definidos, ya que el surgimiento de efectos contrapuestos podría generar importantes costos en términos de eficiencia o equidad. Por ejemplo, un objetivo sería el de cubrir las necesidades de gasto para la provisión de los servicios asignados a los gobiernos departamentales, mientras que otros objetivos consistirían en aumentar la convergencia regional y reducir la dispersión poblacional del territorio.

En cuanto al proceso de implementación del nuevo sistema de transferencias ecualizadoras, se considera que la estrategia más adecuada sería un proceso de implementación gradual basada en el principio de exclusión de responsabilidad (hold harmless) que, al igual que en el caso de México, permitiría una distribución temporal de costos, disminuyendo de esta forma las potenciales resistencias políticas a este proceso de reforma.

Por último, consideramos que el establecimiento de un sistema transparente de cuantificación de las transferencias intergubernamentales sería la reforma más importante que habría que acometer. Como ya se indicó, ello haría necesaria una profunda negociación política con los diferentes actores. No obstante, durante el proceso por el cual dicha reforma se lleva a cabo, y de manera transitoria, 
se pueden plantear ciertas medidas de aplicación inmediata. Por ejemplo, incrementar la capacidad fiscal de los gobiernos departamentales con menor capacidad administrativa mediante la creación de organismos de apoyo que les permitan optimizar los ingresos derivados de los impuestos de propiedad y de otros instrumentos fiscales si se estima necesario. También se podrían considerar las posibles diferencias en los costos de provisión de bienes y servicios públicos en los distintos departamentos, tomando en cuenta la dispersión de la población en el cálculo de las necesidades de gasto per cápita. De ser posible, se ha de aumentar el monto total de las transferencias a fin de que los gobiernos departamentales puedan cubrir la provisión de bienes y servicios que tienen asignados. Dichas propuestas no requieren de una negociación política de envergadura ni la consideración de períodos importantes de transición, dado que su implementación puede ser relativamente inmediata. Sin embargo, cabe insistir en que la mayor reforma requerida debería focalizarse en la configuración de un sistema claro, transparente, simple y consensuado para el cálculo de las transferencias de igualación.

\section{Bibliografía}

Boadway, R. (2015), "Intergovernmental transfers: rationale and policy", Handbook of Multilevel Finance, E. Ahmad y G. Brosio (eds.), Cheltenham, Edward Elgar.

Böhme, K. (2009), The EU Territorial Agenda and its Action Programme: How to Reinforce the Performance, Estocolmo, Ministerio de Empresa, Energía y Comunicaciones.

Brosio, G. y J. Jiménez (2015), "Equalization grants and asymmetrics hearing of natural resources: options for LatinAmerica", Revista de Economía Pública Urbana, № 21, Santiago de Compostela, Universidad de Santiago de Compostela.

Carruthers, J. y G. Ulfarsson (2003), "Urban sprawl and the cost of public services”, Environment and Planning B: Urban Analytics and City Science, vol. 30, N 4, Thousand Oaks, Sage.

Curto-Grau, M., A. Solé-Ollé y P. Sorribas-Navarro (2012), "Partisan targeting of inter-governmental transfers and state interference in local elections: evidence from Spain", IEB Working Paper, № 228, Barcelona, Universidad de Barcelona.

Hortas-Rico, M. y A. Solé-Ollé (2010), "Does urban sprawl increase the costs of providing local public services? Evidence from Spanish municipalities", Urban Studies, vol. 47, № 7, Thousand Oaks, Sage.

Martínez-Vázquez, J. (2015), Nota metodológica para el estudio de las transferencias intergubernamentales y las disparidades fiscales en LAC, Washington, D.C., Banco Interamericano de Desarrollo (BID).

Martínez-Vázquez, J. y C. Sepúlveda (2012), "Toward a more general theory of revenue assignments", International Center for Public Policy Working Paper, № 71, Atlanta, Georgia State University. (2011), "Intergovernmental transfers in Latin America: a policy reform perspective", International Center for Public Policy Working Paper, No. 88, Atlanta, Georgia State University.

Muinelo-Gallo, L., A. Rodríguez y P. Castro (2016), "Intergovernmental transfers and regional income inequalities: an empirical analysis of Uruguay", Hacienda Pública Española, vol. 219, № 4, Madrid, Instituto de Estudios Fiscales.

Muñoz A. y A. Radics (2015), "Oportunidades similares para gobiernos subnacionales diferentes Transferencias de igualación en América Latina y el Caribe", ponencia presentada en las IV Jornadas Iberoamericanas de Financiación Local, Santiago, Comisión Económica para América Latina y el Caribe (CEPAL), 1 y 2 de septiembre.

Musgrave, R. (1959), The Theory of Public Finance, Nueva York, McGraw-Hill.

Oates, W. (1972), Fiscal Federalism, Nueva York, Harcourt Brace Jovanovich.

Solé-Ollé, A. y P. Sorribas-Navarro (2008), "The effects of partisan alignment on the allocation of intergovernmental transfers. Differences-in-differences estimates for Spain”, Journal of Public Economics, vol. 92, № 12, Amsterdam, Elsevier. 


\section{Anexo A1}

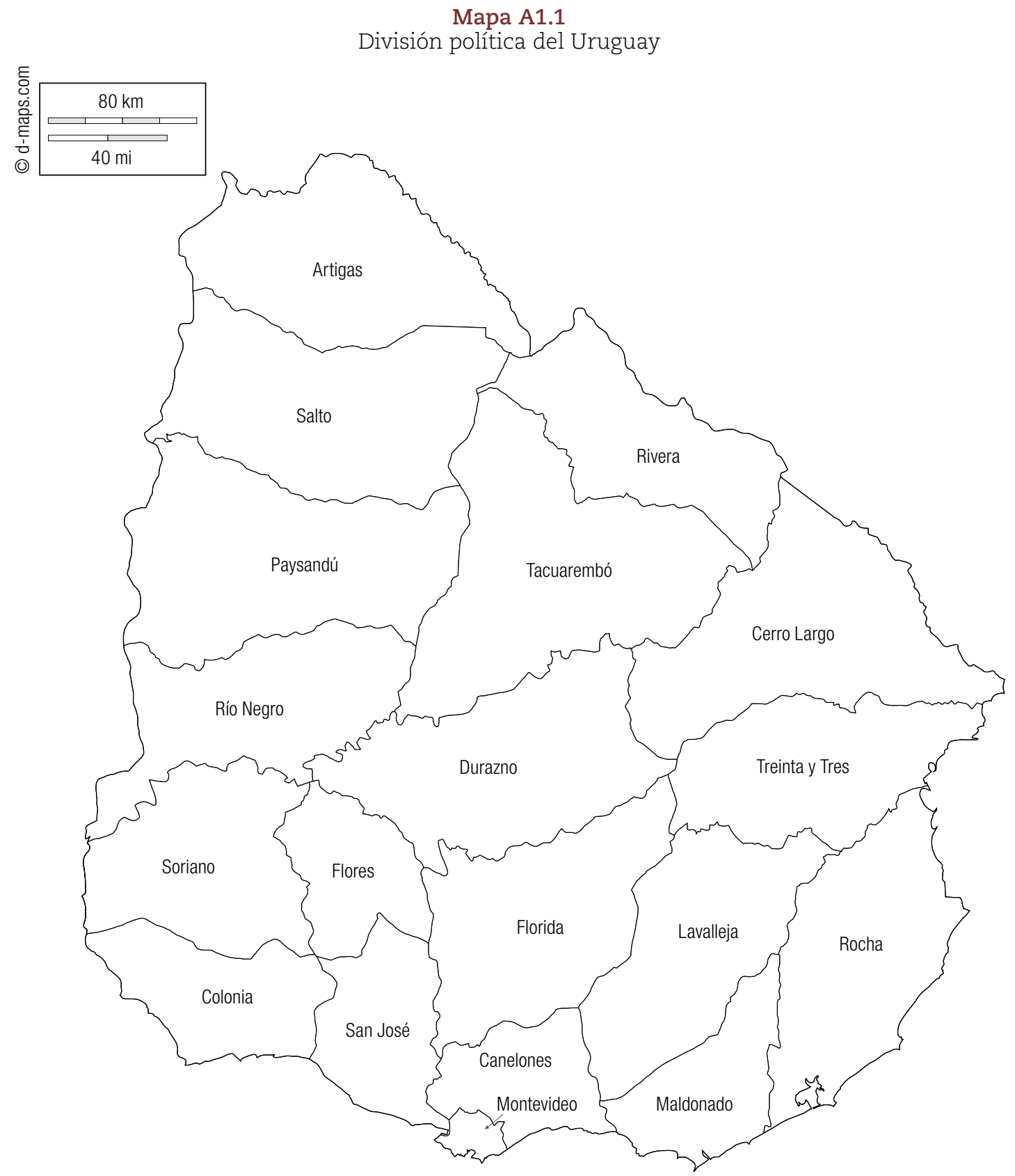

Fuente: Elaboración propia. 


\section{Anexo A2}

\section{Lista de departamentos}

- Artigas

- Canelones

- Cerro Largo

- Colonia

- Durazno

- Flores

- Florida

- Lavalleja

- Maldonado

- Paysandú

- Salto

- San José

- Soriano

- Río Negro

- Rivera

- Rocha

- Tacuarembó

- Treinta y Tres

- Montevideo 


\section{Anexo A3}

\section{Ejercicio de ecualización: metodología}

El procedimiento consiste en evaluar la capacidad de generar ingresos propios por parte de los gobiernos departamentales en relación con sus necesidades de gasto y, a partir de ello, reasignar las transferencias intergubernamentales con un objetivo ecualizador.

Se presenta de forma sintética el procedimiento para determinar las transferencias ecualizadoras. Con fines expositivos se lo resume en seis pasos.

El primer paso consiste en calcular la capacidad fiscal o ingreso estándar per cápita del $G D_{i}\left(I E_{i}\right)$. El $I E_{i}$ se define como la capacidad potencial que tiene un gobierno departamental de recaudar ingresos propios, dada su base imponible y suponiendo que el tipo impositivo es el mismo para todos los departamentos del país:

$$
I E_{i}=\sum_{i=1}^{i=19} B I_{i, j}^{*} T I E A_{j}
$$

Donde $B I_{i j}$ es la base imponible per cápita del rubro de ingreso $j$ en el departamento $i$, mientras que $T I E A_{j}$ es la tasa impositiva efectiva anual del rubro de ingreso $j$ :

$$
\text { TIEA }_{J}=\frac{\text { Ingresos propios totales }_{j}}{\text { Base imponible }_{j}}
$$

El segundo paso consiste en calcular las necesidades de gasto o gasto estándar ajustado $\left(G E A_{i}\right)$ de cada $G D_{i}$. Aquí se asume que en la provisión de bienes públicos la escala juega un rol determinante, dotando a los departamentos con mayor densidad poblacional de ventajas en la prestación de bienes públicos, al disminuir los costos fijos (economías de aglomeración). Una mayor densidad poblacional reduciría los costos, ya sea porque disminuirían el número de centros necesarios para prestar un determinado servicio, los costos de transporte asociados, y la distancia media de los usuarios potenciales respecto al centro de prestación del servicio (Carruthers y Ulfarsson, 2003).

En vista de la importancia de la escala en la provisión de bienes públicos departamentales, se propone realizar un ajuste al gasto estándar por departamento. En este sentido, las necesidades del gasto promedio (GN) se ajustan por un factor que da cuenta de la densidad de población. El factor $D E N S_{i}$ se calcula como la inversa del logaritmo de la densidad de población normalizada entre 1 y 2. De esta forma, obtenemos el gasto estándar ajustado $\left(G E A_{i}\right)$.

$$
G E A_{i}=G N * D E N S_{i}
$$

El tercer paso consiste en calcular la brecha fiscal estandarizada de cada $G D_{i}\left(B r e c h a_{i}\right)$. Del gasto estándar de cada $G D_{i}$ se deduce su ingreso estándar, así como las transferencias condicionadas recibidas por cada uno de ellos $\left(T C_{i}\right)$, en el entendido de que estas últimas también contribuyen a cubrir parte de las necesidades del gasto de los gobiernos departamentales.

$$
\text { Brecha }_{i}=G E A_{i}-I E_{i}-T C_{i}
$$

Este indicador provee la información básica para distribuir un fondo hipotético de transferencias ecualizadoras. 
El cuarto paso consiste en construir el índice de brecha $\left(I B_{i}\right)$, que da cuenta del tamaño relativo del desequilibrio fiscal de cada $G D_{i}$ como porcentaje del desequilibrio fiscal agregado de todos los gobiernos departamentales del país:

$$
I B_{i}=\frac{\text { Brecha }_{i}}{\text { Brecha promedio }}
$$

Se asume que la reasignación de transferencias solo podrá beneficiar a los gobiernos departamentales cuya brecha fiscal sea positiva, lo que permite mejorar la capacidad ecualizadora de las transferencias. De esta manera, a los departamentos con una brecha fiscal negativa se les asigna un $I B_{i}$ igual a cero.

En el quinto paso, a efectos de definir un coeficiente de distribución de las transferencias condicionadas ecualizadoras se calcula el índice de necesidad relativa ponderado $\left(I N R P_{i}\right)$. Se trata de un factor que permite evaluar el índice de brecha departamental en términos de la brecha promedio ponderada y la población de cada departamento.

$$
\operatorname{INRP}_{i}=\frac{I B_{i} *\left(\frac{\text { Población }_{i}}{\text { Poblacióntotal }}\right)}{\sum_{i=1}^{i=19} \operatorname{INRP}_{i}}
$$

Por último, se calculan las transferencias ecualizadoras del sistema (TE), las cuales se obtienen tras multiplicar el monto total de transferencias no condicionadas (TNC) por el índice de necesidad relativa ponderado del $G D_{i}\left(I N R P_{i}\right)$. De esta forma se obtiene el monto de transferencias per cápita correspondiente a cada $G D_{i}$ :

$$
T E_{i}=I N R P_{i} * T N C
$$




\section{Anexo A4}

\section{Cálculo de brechas incrementando el monto total de transferencias}

Cuadro A4.1

Uruguay: distribución de transferencias intergubernamentales en función de las brechas corregidas por densidad de población (incremento del 10\%), 2014

\begin{tabular}{|c|c|c|c|c|c|c|c|}
\hline \multirow{2}{*}{ Departamento } & \multirow{2}{*}{$\begin{array}{c}\begin{array}{c}\text { Índice de } \\
\text { brecha }\end{array} \\
\text { a }\end{array}$} & \multirow{2}{*}{$\begin{array}{c}\begin{array}{c}\text { Ponderador } \\
\text { de población }\end{array} \\
\text { b }\end{array}$} & \multirow{2}{*}{$\begin{array}{c}\begin{array}{c}\text { Coeficiente de } \\
\text { distribución }\end{array} \\
\mathrm{c}=\mathrm{a}^{\star} \mathrm{b}\end{array}$} & \multirow{2}{*}{$\begin{array}{r}\begin{array}{r}\text { Distribución } \\
\text { ecualizadora }\end{array} \\
\text { (en millones }\end{array}$} & \multirow{2}{*}{$\begin{array}{c}\text { Distribución } \\
\text { actual }\end{array}$} & \multicolumn{2}{|c|}{ Cambio } \\
\hline & & & & & & (en millones de pesos) & $\begin{array}{c}\text { (en } \\
\text { porcentajes) }\end{array}$ \\
\hline Artigas & 5,28 & 0,02 & 0,12 & 457 & 353 & 104,71 & 30 \\
\hline Canelones & 3,01 & 0,16 & 0,47 & 1813 & 836 & 976,67 & 117 \\
\hline Cerro Largo & 5,01 & 0,03 & 0,13 & 504 & 422 & 81,66 & 19 \\
\hline Colonia & 1,24 & 0,04 & 0,05 & 177 & 317 & $-140,13$ & -44 \\
\hline Durazno & 5,04 & 0,02 & 0,09 & 337 & 378 & $-40,58$ & -11 \\
\hline Flores & 2,12 & 0,01 & 0,02 & 63 & 188 & $-125,29$ & -67 \\
\hline Florida & 4,31 & 0,02 & 0,09 & 338 & 321 & 16,44 & 5 \\
\hline Lavalleja & 4,77 & 0,02 & 0,09 & 327 & 347 & $-20,38$ & -6 \\
\hline Maldonado & 0,00 & 0,05 & - & - & 512 & $-511,70$ & -100 \\
\hline Montevideo & 0,75 & 0,40 & 0,30 & 1160 & 1065 & 95,16 & 9 \\
\hline Paysandú & 4,28 & 0,03 & 0,15 & 567 & 454 & 112,39 & 25 \\
\hline Rio Negro & 3,07 & 0,02 & 0,05 & 194 & 300 & $-105,82$ & -35 \\
\hline Rivera & 4,28 & 0,03 & 0,13 & 516 & 391 & 124,35 & 32 \\
\hline Rocha & 4,80 & 0,02 & 0,10 & 396 & 420 & $-24,81$ & -6 \\
\hline Salto & 4,40 & 0,04 & 0,17 & 638 & 492 & 146,03 & 30 \\
\hline San José & 3,08 & 0,03 & 0,10 & 382 & 310 & 72,02 & 23 \\
\hline Soriano & 3,63 & 0,03 & 0,09 & 348 & 382 & $-33,47$ & -9 \\
\hline Tacuarembó & 5,32 & 0,03 & 0,15 & 559 & 425 & 134,35 & 32 \\
\hline Treinta y Tres & 5,24 & 0,01 & 0,08 & 299 & 336 & $-36,67$ & -11 \\
\hline
\end{tabular}

Fuente: Elaboración propia. 


\section{Cuadro A4.2}

Uruguay: distribución de transferencias intergubernamentales en función de las brechas corregidas por densidad de población (incremento del 20\%), 2014

\begin{tabular}{|c|c|c|c|c|c|c|c|}
\hline \multirow{3}{*}{$\begin{array}{l}\text { Departamento } \\
\text { Artigas }\end{array}$} & \multirow{3}{*}{$\begin{array}{c}\begin{array}{c}\text { Índice de } \\
\text { brecha }\end{array} \\
\text { a } \\
5,28\end{array}$} & \multirow{3}{*}{$\begin{array}{c}\begin{array}{c}\text { Ponderador } \\
\text { de población }\end{array} \\
\text { b } \\
0,02\end{array}$} & \multirow{3}{*}{$\begin{array}{c}\begin{array}{c}\text { Coeficiente de } \\
\text { distribución }\end{array} \\
\mathrm{c}=\mathrm{a}^{\star} \mathrm{b} \\
0,12\end{array}$} & \multirow{2}{*}{$\begin{array}{c}\begin{array}{c}\text { Distribución } \\
\text { ecualizadora }\end{array} \\
\text { (en millones }\end{array}$} & \multirow{2}{*}{$\begin{array}{c}\begin{array}{c}\text { Distribución } \\
\text { actual }\end{array} \\
\text { de pesos) }\end{array}$} & \multicolumn{2}{|c|}{ Cambio } \\
\hline & & & & & & \multirow{2}{*}{$\frac{\text { (en millones de pesos) }}{146,28}$} & \multirow{2}{*}{$\frac{\text { (en porcentajes) }}{41}$} \\
\hline & & & & 499 & 353 & & \\
\hline Canelones & 3,01 & 0,16 & 0,47 & 1977 & 836 & 1141,46 & 137 \\
\hline Cerro Largo & 5,01 & 0,03 & 0,13 & 550 & 422 & 127,48 & 30 \\
\hline Colonia & 1,24 & 0,04 & 0,05 & 193 & 317 & $-124,08$ & -39 \\
\hline Durazno & 5,04 & 0,02 & 0,09 & 368 & 378 & $-9,90$ & -3 \\
\hline Flores & 2,12 & 0,01 & 0,02 & 69 & 188 & $-119,57$ & -63 \\
\hline Florida & 4,31 & 0,02 & 0,09 & 368 & 321 & 47,13 & 15 \\
\hline Lavalleja & 4,77 & 0,02 & 0,09 & 356 & 347 & 9,31 & 3 \\
\hline Maldonado & 0,00 & 0,05 & - & - & 512 & $-511,70$ & -100 \\
\hline Montevideo & 0,75 & 0,40 & 0,30 & 1265 & 1065 & 200,61 & 19 \\
\hline Paysandú & 4,28 & 0,03 & 0,15 & 618 & 454 & 163,89 & 36 \\
\hline Rio Negro & 3,07 & 0,02 & 0,05 & 212 & 300 & $-88,14$ & -29 \\
\hline Rivera & 4,28 & 0,03 & 0,13 & 563 & 391 & 171,22 & 44 \\
\hline Rocha & 4,80 & 0,02 & 0,10 & 432 & 420 & 11,15 & 3 \\
\hline Salto & 4,40 & 0,04 & 0,17 & 696 & 492 & 204,04 & 41 \\
\hline San José & 3,08 & 0,03 & 0,10 & 417 & 310 & 106,74 & 34 \\
\hline Soriano & 3,63 & 0,03 & 0,09 & 380 & 382 & $-1,81$ & 0 \\
\hline Tacuarembó & 5,32 & 0,03 & 0,15 & 610 & 425 & 185,19 & 44 \\
\hline Treinta y Tres & 5,24 & 0,01 & 0,08 & 326 & 336 & $-9,47$ & -3 \\
\hline
\end{tabular}

Fuente: Elaboración propia. 


\title{
Alcances sociales y económicos de la implementación de la hipoteca inversa en Chile
}

\author{
José Luis Ruiz, Pablo Tapia y José Donoso
}

\section{Resumen}

Este estudio simula los alcances sociales y económicos de implementar la hipoteca inversa en Chile. Usando la Encuesta de Protección Social (EPS, 2009) y metodologías de simulación recientes se analiza el aporte monetario que lleva aparejado la contratación de este instrumento, que consiste en un sistema de pagos periódicos de manera vitalicia. Los individuos que podrían acceder a la hipoteca inversa serían aquellos pensionados y propietarios de su vivienda, lo que supone el $70 \%$ de la población constituida por personas mayores. El aporte monetario es creciente a tasas que van en aumento en función de la edad en que se contrata la hipoteca inversa. Por último, se señala que el aumento de liquidez tiene un amplio potencial social, pudiendo disminuir un 15\% el índice de pobreza en el grupo objetivo.

\section{Palabras clave}

Vivienda, financiación de la vivienda, hipotecas, pensiones, jubilación, precios, aspectos económicos, modelos matemáticos, aspectos sociales, Chile

\section{Clasificación JEL}

G21, G22, G28

\section{Autores}

José Luis Ruiz Vergara es Profesor Asistente en el Departamento de Administración de la Universidad de Chile. Correo electrónico: jlruiz@fen.uchile.cl.

Pablo Tapia Griñen es Profesor Asistente en el Departamento de Administración de la Universidad de Chile. Correo electrónico: ptapia@fen.uchile.cl.

José Donoso Salas es Magíster en Finanzas de la Universidad de Chile. Correo electrónico: sjdonososa@fen.chile.cl. 


\section{Introducción}

La tendencia demográfica mundial en las últimas décadas es de aumentos en longevidad y en la proporción de personas mayores sobre la población total. Según datos del Instituto Nacional de Estadísticas de Chile (INE), en 1950 la población mayor de 65 años en Chile representaba el 4\% de la población, cifra que ha ido en aumento y que se proyecta alcanzará el 22\% en 2025. Por ende, las personas que forman parte de este grupo etario cobran mayor importancia para el diseño de políticas públicas y representan un desafío para el financiamiento de los sistemas de pensiones. Lo anterior adquiere carácter urgente si consideramos que actualmente las pensiones que reciben los chilenos son bajas en comparación con los países pertenecientes a la Organización para la Cooperación y el Desarrollo Económicos (OCDE) y que el $70 \%$ de la población considera que estas son insuficientes para mantener un nivel de vida adecuado (Comisión Asesora Presidencial sobre el Sistema de Pensiones, 2015).

Una alternativa que puede contribuir a mejorar el nivel de vida de los pensionados es la hipoteca inversa, conocida también como hipoteca revertida o hipoteca reversa. En términos generales, la hipoteca inversa es un producto financiero dirigido a personas jubiladas propietarias de su vivienda, en virtud del cual una institución financiera se compromete a pagar un monto de forma mensual hasta que el contratante fallezca, luego de lo cual la propiedad pasa a posesión del financista, a menos que los herederos devuelvan a la institución financiera el monto total comprometido. El principal objetivo de este instrumento es desbloquear parte de la riqueza ilíquida que representa la propiedad de una vivienda sin que el propietario tenga que dejar de habitarla. Lo anterior conllevaría una serie de beneficios económicos, como son el aumento en la liquidez de los hogares y la obtención de recursos que complementan a la pensión y generan reducción de pobreza entre las personas mayores. Sin embargo, la hipoteca inversa no está presente en Chile, por lo que el objetivo del presente estudio es simular los alcances sociales y económicos que podría generar la implementación de este instrumento financiero.

Para llevar a cabo la investigación se sigue la metodología propuesta por Ma y Deng (2013) y Wang y Kim (2014), a fin de modelar los pagos mensuales de una hipoteca inversa a partir un precio de vivienda ${ }^{1}$. Partiendo de los pagos generados de la hipoteca inversa, se analiza cuál es el aporte de estos al ingreso de la familia y a nivel per cápita, cómo cambian los pagos con respecto a la edad de contratación de la hipoteca inversa una vez pensionado, y en qué medida puede incidir el instrumento en la tasa de pobreza del grupo objetivo.

La hipoteca inversa ha sido analizada en Chile por Muñoz (2011) y por Alonso, Tuesta y Lamuedra (2013). Por su parte, nuestra investigación se enfoca en el potencial social de este instrumento utilizando simulaciones en base a modelamientos actualizados, con variantes como la relación préstamo-valor, el cambio en el precio de los inmuebles y las tasas de mortalidad, entre otras. Estas innovaciones dotan de mayor interés a esta investigación: aunque esté inmersa en un tipo de literatura ampliamente documentada, esto le proporciona una plataforma confiable donde contrastar nuestros hallazgos.

Según nuestro análisis, la contratación de una hipoteca inversa daría lugar a pagos mensuales de 62.508 pesos chilenos en promedio para los contratantes, lo que supone un aumento del 107\% con respecto a la pensión que reciben mensualmente los individuos de la muestra, cuya media es de 58.245 pesos. A su vez, la contribución monetaria del instrumento conlleva un incremento de liquidez correspondiente al $57 \%$ del ingreso per cápita. Además, se presenta evidencia de que a medida que aumenta la edad en que las personas contratan el instrumento se incrementan los pagos que estos

\footnotetext{
1 Estos precios corresponden a la Encuesta de Protección Social 2009 ([véase [en línea]), https://www.previsionsocial.gob.cl/ sps/biblioteca/encuesta-de-proteccion-social/bases-de-datos-eps/.
} 
perciben, ya que aumentan las tasas. Consecuentemente, en el caso de que todas las personas aplicables contraten una hipoteca inversa al momento de jubilarse, el índice de pobreza en este grupo se reduciría aproximadamente en un 15\%. Este resultado puede ser ampliado en caso de aumentar la edad de jubilación de las mujeres a 65 años e igualarla a la de los hombres, llegando a un 19\% de reducción de pobreza.

Luego de la presente introducción el documento prosigue con la sección II, donde se detalla el contexto de las pensiones en Chile. En la sección III se revisa la literatura teórica y empírica de la hipoteca inversa y su potencialidad social. En la sección IV se presentan el marco analítico y los datos de la simulación. En la sección $\vee$ se muestran los resultados de simulaciones. Por último, en la sección VI figuran las conclusiones.

\section{Pensiones en Chile}

Hasta 1980 Chile contaba con un sistema de pensiones basado en el reparto, en virtud del cual las jubilaciones se financiaban en distintas instituciones previsionales llamadas cajas de previsión, con reglas y beneficios diferenciados. Dada la tendencia al envejecimiento de la población y a una menor tasa de trabajadores activos que contribuían a su financiamiento el sistema se volvió insolvente, razón por la cual en 1981 se creó un nuevo sistema de pensiones basado en la capitalización de cuentas individuales para los trabajadores que se incorporan al mercado laboral y en forma voluntaria a quienes venían del sistema antiguo. Quienes se mantuvieron en el sistema antiguo siguieron contribuyendo a este, pero sus jubilaciones se pagan con impuestos generales de la nación. Los afiliados al nuevo sistema de pensiones depositan cotizaciones previsionales en cuentas individuales gestionadas por Administradoras de Fondos de Pensiones (AFP), que a su vez están encargadas de recaudar, registrar e invertir los recursos previsionales. Las AFP se encargan también del pago de pensiones bajo la modalidad de retiros programados ${ }^{2}$, mientras que de la modalidad de las rentas vitalicias ${ }^{3}$ se ocupan las compañías de seguros de vida.

El objetivo principal de todo sistema de pensiones es asegurar un ingreso estable a los trabajadores cuando concluyen su vida laboral, esperando que dicho ingreso se corresponda a aquellos que percibió durante su vida activa. El sistema antiguo basado en el reparto otorga tasas de reemplazo del orden del $70 \%$ a quienes cumplen los requisitos ${ }^{4}$. El actual sistema presenta una serie de ventajas con respecto al sistema del reparto; no obstante, este modelo no resuelve por sí sólo el financiamiento de la vejez en países con mala distribución del ingreso, como es el caso de Chile (Superintendencia de Pensiones, 2010).

Transcurridas tres décadas del sistema de capitalización individual se diagnosticó que había una gran parte de la población que no contaba con los ahorros suficientes para financiar en forma digna su vejez. Ello se explica por la baja densidad en las contribuciones por cotizaciones de los individuos (Superintendencia de Pensiones, 2006), así como por las diferencias de remuneraciones por género y otros factores. En 2008 se introdujo la principal reforma al sistema actual de pensiones, cuyo principal avance consistió en introducir un pilar solidario cuyo objetivo es la prevención de la pobreza y que se financia con impuestos generales (Superintendencia de Pensiones, 2010). Se trató de un avance, pero no fue suficiente. En 2015 se creó la Comisión Asesora Presidencial sobre el Sistema de Pensiones (CAPSP), a la que se encargó hacer un diagnóstico y formular propuestas de mejoras al sistema de pensiones. En el informe se indica que el $50 \%$ de los jubilados reciben pensiones inferiores

\footnotetext{
2 Véase [en línea] https://www.spensiones.cl/portal/institucional/594/w3-propertyvalue-9924.html\#faqs.

3 Véase [en línea] https://www.spensiones.cl/portal/institucional/594/w3-propertyvalue-9924.html\#faqs.

4 No se paga pensión a quienes contribuyeron al sistema durante menos de 15 años.
} 
a 82.650 pesos, con una brecha importante entre mujeres y hombres. La mediana de las pensiones de las mujeres es de 42.561 pesos, mientras que para los hombres es de 112.333 pesos. La mitad de los jubilados chilenos recibe como máximo un 34\% del promedio de su salario de los últimos diez años antes de entrar a la etapa pasiva. En este aspecto, el resultado anterior incluye a los jubilados con arreglo al sistema de pensiones previo a 1980. Así bien, se estima que aislando a los individuos del sistema de capitalización individual y tomando como horizonte a los pensionados en los años 2025 y 2035, la mitad de las personas no superarían el 37\% de las cifras antes mencionadas. Más aún, el valor anterior es extremadamente bajo en comparación con el promedio de la OCDE, equivalente a una tasa de reemplazo del $66 \%$.

Por último, y muy estrechamente relacionado con lo anterior, el 70\% de los chilenos opinan que los montos de las pensiones son insuficientes para costear un nivel de vida adecuado (OCDE, 2013). Esto motivó movilizaciones sociales en 2016 en demanda de cambios del modelo de pensiones para así optar a mejores beneficios (The Economist, 2016).

\section{Literatura sobre hipoteca inversa}

Una de las mayores disyuntivas que enfrentan los pensionados con respecto a su vivienda es si han de permanecer en ella, exponiéndose a una menor liquidez de la que se habían acostumbrado en su vida laboral, o bien vender el inmueble y destinar parte del dinero al pago de un arriendo, utilizando el monto excedente con el fin de aumentar sus ingresos (Bartel y Daly, 1980). Esta última opción es racional desde un punto de vista económico; sin embargo, arrendar y exponerse a cambios de propiedad conlleva importantes costos psicológicos (Davidoff, 2010). Una posible solución a tal problemática es la hipoteca inversa, también conocida como hipoteca reversa o hipoteca revertida. Se trata de un producto financiero que surgió en los Estados Unidos en los años ochenta y se ha expandido por distintas partes del mundo (hoy está presente también en el Canadá, Australia, España y el Japón, entre otros). Con dicho instrumento los pensionados y propietarios de viviendas pueden solicitar un préstamo usando su inmueble como colateral sin tener que abandonarlo.

Según Phillps y Gwin (1993) existen tres tipos principales de hipoteca inversa: la hipoteca conocida como hipoteca inversa a plazo (term reverse mortgage), que consiste en pagos de suma fija por un período determinado después de concluido el cual se reembolsa el préstamo vendiendo la propiedad; la hipoteca inversa con plazo dividido (split-term reverse mortgage), que emula las condiciones precedentes, pero con la diferencia de que en esta las personas continúan viviendo en su hogar luego de terminados los pagos y el préstamo se reembolsa solo cuando el prestatario fallece, se muda o vende la propiedad; por último está la hipoteca con plan de pagos mensuales (tenure reverse mortgage), considerablemente más utilizada que las anteriores y que consiste en pagos de suma fija hasta que el individuo fallece, se muda o vende la propiedad, en la que el monto del préstamo depende positivamente de la edad del prestatario junto con el valor de la propiedad, y negativamente de la tasa de interés (Fornero, Rossi y Urzi, 2016).

Se argumenta que los individuos que adquieren una hipoteca inversa son personas mayores ricas pero pobres en dinero en efectivo, es decir, personas de edad dueñas de una considerable riqueza (representada por el elevado valor de su inmueble) pero con restricciones de liquidez (Moulton y otros, 2015). En este sentido, Nakajima y Telyukova (2017) analizan que las características preponderantes para la toma del instrumento son tener ingresos bajos, poseer un inmueble caro, no tener una hipoteca pendiente, estar solo y padecer de mala salud.

Por su parte, antes de poner en práctica la hipoteca inversa se realizaron simulaciones en distintos países a fin de determinar su potencialidad. Los resultados al respecto han sido diversos. 
Uno de los estudios más pertinentes en relación con las simulaciones es el de Mayer y Simons (1994), realizado en etapas iniciales de la aplicación de la hipoteca inversa en los Estados Unidos. En ese estudio, los autores señalan que la contratación de una hipoteca inversa permitiría reducir cerca de tres cuartas partes de la pobreza en el grupo objetivo. Los autores proceden a convertir el valor de la propiedad en anualidades con periodicidad de pago mensual (tenure). Así bien, por falta de datos y metodologías avanzadas, se realizan supuestos arbitrarios en lo referente al valor de las propiedades y el coeficiente préstamo-valor. Esta última variable es la más criticable, pues corresponde al porcentaje del inmueble que los individuos pueden utilizar como colateral. Los autores la fijan en un $75 \%$, siendo que en estudios posteriores esta se obtiene matemáticamente, lo que da lugar a valores menores.

Kutty (1998) realiza su estudio post implementación de la hipoteca inversa en los Estados Unidos. Con arreglo a un instrumento de periodicidad de pago mensual, sostiene que si todo el grupo objetivo contratara una hipoteca inversa, menos de un tercio saldría de la pobreza. En el Reino Unido, Hancock (1998) realiza una simulación de la puesta en práctica de la hipoteca inversa siguiendo una metodología idéntica a la de Kutty (1998), y llega a la conclusión de que la reducción de la pobreza sería menor al 5\%. Estos resultados divergentes pueden ser parcialmente atribuidos a que en los Estados Unidos el instrumento no está sujeto a tributación mientras que en el Reino Unido sí, por lo que en este último caso los pagos se ven reducidos (Ong, 2008).

Moscarola y otros (2015) analizan el potencial social de la implementación de la hipoteca inversa en países europeos en los cuales aún no existe este instrumento. Los autores simulan cuánto se reduciría la pobreza en el grupo objetivo tomando en consideración tres escenarios con tasas de descuento arbitrarias y dos escenarios con distintos porcentajes de uso del inmueble como colateral. España y Bélgica son los países con mayor potencial, con una reducción de pobreza máxima cercana al 25\%. Por su parte, Francia e Italia podrían alcanzar cifras de disminución de más del 10\%, mientras que en los demás países analizados (Suiza, Austria, Holanda, Alemania y Dinamarca) la reducción sería menor.

En Chile, Muñoz (2011) señala que si todo el grupo objetivo contratara la hipoteca inversa, la pobreza se reduciría en un 88\%. Sin embargo, este autor no considera una modalidad de periodicidad de pago mensual, sino un plazo dividido (split term). Además, el estudio no analiza la mayor liquidez otorgada por el instrumento en términos per cápita, como en la mayoría de los estudios internacionales, ni tampoco incluye una desagregación de los resultados en distintos grupos de interés. Fuentes y Moris (2014) examinan la factibilidad legal de la implementación de la hipoteca inversa en Chile, concluyendo que existe un panorama propicio, dado que el entorno jurídico vigente permite la efectiva configuración del contrato, existiendo además mecanismos legales idóneos que brindan protección a las partes.

Nuestro artículo se basa en la metodología utilizada por Ma y Deng (2013) y Wang y Kim (2014), quienes introducen el principio de la fijación de los precios de los seguros. Este principio consiste en realizar una simulación en la que se evitan utilidades negativas para el prestamista, considerando el hecho de que los pagos al prestatario podrían superar el precio de la vivienda en un momento dado, como cuando la apreciación de la vivienda sea menor a la esperada o el contratante viva más de lo estimado: se estaría así tomando en cuenta la relación entre un seguro de garantía y las posibles pérdidas que podría sufrir el prestamista. En los estudios anteriores no se había incluido esta interconexión, por lo que se restaba importancia a la relación descrita. Por lo tanto, al permitir que la institución financiera defina los pagos mensuales en el punto de equilibrio donde los valores esperados de los seguros recibidos sean equivalentes al valor esperado de las pérdidas, se logra que los pagos se ajusten más a la realidad, lo cual resulta fundamental para motivar a las instituciones financieras a participar en este tipo de mercado. No obstante, el método de simulación de estos autores no ha sido aplicado con el objetivo de analizar el impacto social de la hipoteca inversa, por lo que el presente estudio será pionero en este aspecto. 
Por último, más allá de la potencialidad teórica del instrumento, pasadas tres décadas desde su creación, su implementación y uso se encuentran por debajo de lo esperado (Davidoff, Gerhard y Post, 2017). En efecto, en los Estados Unidos en 2011 este producto financiero fue utilizado por solo el 2,1\% del total de las personas que podrían hacerlo: se trata del porcentaje más alto obtenido hasta la fecha (Nakajima y Telyukova, 2017). Davidoff, Gerhard y Post (2017) sostienen que esa cifra se debe a que los grupos objetivo no entienden bien el instrumento. Lo anterior se complementa con el estudio de Moulton y otros (2015), quienes afirman que la hipoteca inversa tiene una reducida tasa de uso debido a que las personas de edad tienen aversión a los instrumentos financieros complejos o bien no entienden a cabalidad lo que se les está ofreciendo.

\section{Metodología y datos}

\section{Marco analítico}

A fin de calcular las rentas mensuales se utilizará una hipoteca inversa de periodicidad de pago mensual, que se encuentra ampliamente documentada y nos brinda una plataforma confiable donde comparar los resultados obtenidos. Luego se procede con arreglo a Ma y Deng (2013) y a Wang y Kim (2014), en que dichos pagos mensuales se calculan utilizando el precio del inmueble de los individuos al entrar en vigor el contrato. Se establece un precio arbitrario del inmueble a efectos de evidenciar cómo cambian los pagos mensuales si el contratante toma una hipoteca inversa en distintos tramos etarios, teniendo en cuenta el mismo valor de la propiedad. En nuestro estudio seguimos este mismo proceso, pero utilizamos el valor real de la vivienda que usarían como colateral los individuos.

Para referenciar los precios de las viviendas se utilizó la Encuesta de Protección Social (EPS) 2009, que es representativa a nivel poblacional y cuenta con información detallada y ratificada de los pensionados, que es el grupo de interés. No obstante lo anterior, el modelo requiere obtener el valor del inmueble al momento de la jubilación de cada individuo. Para esto se utiliza la simulación de Ma y Deng (2013) y Wang y Kim (2014), agregando un nivel previo para la obtención de esta variable utilizando los valores correspondientes a 2009 para cada persona. Por otro lado, el presente estudio presenta la metodología de estos autores en cuanto a los pagos mensuales, incorporando en extenso el uso de las tablas de mortalidad (Superintendencia de Pensiones, 2009a).

El algoritmo utilizado para simular los pagos mensuales tiene en cuenta lo siguiente:

i) el precio de la vivienda imputado en la EPS 2009;

ii) la determinación del precio de la vivienda a la edad de jubilación;

iii) la determinación del precio de la vivienda al término del contrato;

iv) la determinación de la relación préstamo-valor, y

v) la determinación de los pagos mensuales (utilizando las tablas de mortalidad).

La modelación comienza con el precio de vivienda imputado a 2009 como variable base, cuya obtención se explica en el apartado IV.3. Luego se procede de la siguiente manera:

a) A partir del precio de la vivienda imputado a 2009 para el individuo $i,\left(P_{2009, i}\right)$, para cada persona se estima el precio de vivienda al momento de jubilarse $\left(P_{J, i}\right)$, el cual se basa en la metodología expuesta por Szymanoski (1994). Véase una descripción de esta metodología en el anexo A1.

$$
P_{J, i}=\frac{P_{2009, i}}{\exp \left(\mu \cdot t_{i}+0,5 \cdot \sigma^{2} \cdot t_{i}\right)}
$$


Donde $\mu$ corresponde al índice promedio del crecimiento anual del precio de venta de los inmuebles (Banco Central de Chile) en la economía y $\sigma^{2}$ representa la varianza del mismo índice de crecimiento, mientras que $t_{i}$ señala los años transcurridos desde la jubilación del individuo $i$ hasta 2009, según la información extraída de la EPS 2009.

b) Luego de obtenido el precio de vivienda al jubilarse se estima el precio de vivienda al término del contrato $\left(P_{T, i}\right)$, aproximable al precio del inmueble cuando el individuo $i$ cumple su expectativa de vida (con arreglo a Szymanoski, 1994).

$$
P_{T, i}=P_{J, i} \cdot \exp \left(\mu \cdot T_{i}+0,5 \cdot \sigma^{2} \cdot T_{i}\right)=\frac{P_{2009, i} \cdot \exp \left(\mu \cdot T_{i}+0,5 \cdot \sigma^{2} \cdot T_{i}\right)}{\exp \left(\mu \cdot t_{i}+0,5 \cdot \sigma^{2} \cdot t_{i}\right)}
$$

En este caso $T_{i}$ representa el valor esperado de la duración del contrato en años, es decir, la esperanza de vida de $i$, menos la edad de jubilación, la que se obtiene combinando la información del Instituto Nacional de Estadística (2010a) y las tablas de mortalidad disponibles en la Superintendencia de Pensiones. A su vez, los valores de la esperanza de vida como la edad de jubilación dependerán del género del individuo.

c) Se obtiene la relación préstamo-valor (RPV), que corresponde al porcentaje máximo que el individuo puede usar como colateral del precio de vivienda al jubilarse, lo que se describe en la ecuación (3).

$$
R P V_{i}=\frac{P_{T, i} /(1+r)^{T_{i}}}{P_{J, i}}
$$

Donde $r$ representa la tasa de descuento del préstamo, la cual se compone de la suma lineal de la tasa de interés libre de riesgo ${ }^{5}$ de la economía $\left(i_{i r}\right)$, la tasa de seguro de garantía mensual $^{6}\left(T S G_{m}\right)$ y el margen del prestamista ${ }^{7}(M P)$. Estos componen los elementos que caracterizaran a la economía nacional.

d) Se calcula el valor presente del préstamo (VPP), que puede entenderse como el monto que financia la institución financiera en caso de que solo se realice un pago de suma alzada al momento de firmar el contrato, tal como se describe en la ecuación (4), donde se incluye la tasa de seguro de garantía inicial ${ }^{8}$ del contrato $\left(T S G_{0}\right)$

$$
V P P_{i}=P_{J, i} \cdot\left(R P V_{i}-T S G_{0}\right)
$$

e) Con arreglo a Wang y Kim (2014), se determinan los pagos mensuales de acuerdo a la ecuación (5), donde $\tau_{i}$ representa el valor esperado de la duración del contrato en meses.

$$
P M_{i}=\frac{V P P_{i}}{\sum_{n=0}^{n=\left(\tau_{i}-1\right)}(1+r)^{-n}}
$$

\footnotetext{
5 Media mensual de la tasa de interés del mercado secundario de los bonos licitados por el Banco Central de Chile (BCP) a 10 años en 2009 (véase en línea]https://si3.bcentral.cl/Boletin/secure/boletin.aspx?idCanasta=1MRMW2951).

6 Se utiliza la tasa del 0,5\% vigente en el mercado estadounidense (Rodda y otros, 2003). La misma tasa se utiliza en los artículos acerca de la metodología seguida (Wang y Kim2014; Ma y Deng, 2013).

7 Variable que varía normalmente entre el $1 \%$ y el $2 \%$ (Rodda, Herbert y Lam, 2000). Se utiliza el $1 \%$ siguiendo a Wang y $\operatorname{Kim}$ (2014).

8 Se utiliza la tasa del $2 \%$ vigente en el mercado estadounidense (Rodda y otros, 2003). La misma tasa se utiliza en el artículo acerca de la metodología seguida (Wang y Kim, 2014).
} 
La ecuación (5) proporciona el monto para los pagos mensuales en el supuesto de que todos los individuos vivan la cantidad de años que se indica en su esperanza de vida. Sin embargo, esto puede resultar poco realista, ya que en la práctica los individuos pueden fallecer antes o después de esa fecha. Esto nos podría dar una idea equivocada acerca de los pagos mensuales, por lo que, y con el propósito de mejorar los alcances de la simulación, extenderemos la ecuación (5) incluyendo un factor de descuento que considere la probabilidad de que $i$ se encuentre vivo para recibir el pago en el mes $N,\left(p_{N, i}\right)$, siempre que estuviera vivo al momento de contratar la hipoteca inversa, tal como se expresa en la ecuación (6).

$$
P M_{i}=\frac{V P P_{i}}{\sum_{N=0}^{N=T}\left[(1+r)^{-N} \cdot\left(p_{N, i}\right)\right]}
$$

Donde el término $T$ simboliza el período en el que la probabilidad de sobrevivencia alcance el valor de 0 .

Un aspecto importante a tener en cuenta respecto a la ecuación (6) es que en el presente estudio $p_{N, i}$ se obtendrá a través de las tablas de mortalidad del sistema de pensiones de Chile a 2009 (véase el anexo A2), donde la probabilidad de fallecer se presenta de forma anual y no mensual como requiere la modelación. Por ese motivo, supondremos que la probabilidad de que un individuo esté vivo en un año determinado será igual a la probabilidad de que el mismo individuo viva en cada mes dentro de ese año. Por otro lado, las tablas de mortalidad del sistema de pensiones de Chile al 2009 también determinan el valor límite $T$ (110 años para ambos géneros). Así bien, esto corresponde al mes $T=540$ de duración del contrato para un individuo que se jubile a los 65 años y mes $T=600$ para un individuo que se jubile a los 60 años.

\section{Parámetros de la economía}

La modelación requiere conocer parámetros específicos de la economía chilena, a saber:

\section{Tasa de descuento de la hipoteca inversa}

En la literatura especializada la tasa de descuento que se utiliza para el cálculo de los pagos por concepto de hipoteca inversa se obtiene como la suma de una tasa libre de riesgo, generalmente a diez años, más un diferencial por concepto de margen al prestamista y otro para cancelar un seguro de garantía mensual que se paga a lo largo de la duración del préstamo. Luego, se considera como tasa libre de riesgo del Banco Central de Chile a diez años en pesos (BCP-10), cuyo promedio anual en 2009 era del 5,67\%. A su vez, el margen al prestamista y seguro de garantía mensual serán del 1\% y el 0,5\% en tasas anuales (Rodda, Hebbert y Lam, 2000), respectivamente. Los valores anteriores son los utilizados en la hipoteca inversa en los Estados Unidos.

\section{Costo inicial del préstamo}

Dicho costo corresponde al precio del inmueble al momento de contratar el instrumento, multiplicado por una tasa de garantía inicial del 2\% (utilizada en Ma y Deng (2013) y en Wang y Kim (2014)). 


\section{Media y desviación estándar del cambio porcentual del precio de las viviendas}

Las variables con respecto al movimiento en el precio de las viviendas se obtienen utilizando el índice del precio de inmuebles provisto por el Banco Central de Chile, disponible desde 2003 a 2014. Así bien, se utiliza la media simple del cambio en el índice anual y su desviación estándar en todo este periodo. Las cifras anteriores fueron del $4,4 \%$ y el $2,9 \%$, respectivamente.

\section{Esperanza de vida y tablas de mortalidad}

Para determinar la esperanza de vida de los individuos de nuestra muestra se utiliza la tabla de mortalidad de Chile al 2009. Los valores para la esperanza del horizonte de vida son de 76 años para los hombres y 81 años para las mujeres (INE, 2010b). Por su parte, para determinar las probabilidades de supervivencia de los individuos en los años en que está vigente el contrato se utilizan las tablas de mortalidad para pensiones de renta vitalicia en Chile a 2009, diferenciadas por género. Las tablas de mortalidad figuran en el anexo A2.

Existen diferencias por género en torno a la probabilidad de sobrevivencia. Se muestran las probabilidades de sobrevivencia de hombres que se jubilan a los 65 años y de mujeres que se jubilan a los 60 y 65 años, considerando los 110 años como edad límite para ambos géneros, de forma que a cada edad los hombres tienen una menor probabilidad de estar vivos, en comparación con las mujeres, lo cual se magnifica en las edades medias del tramo de vida analizado (véase el gráfico 1).

\section{Gráfico 1}

Probabilidad de sobrevivencia por sexo y edad de jubilación (En porcentajes)

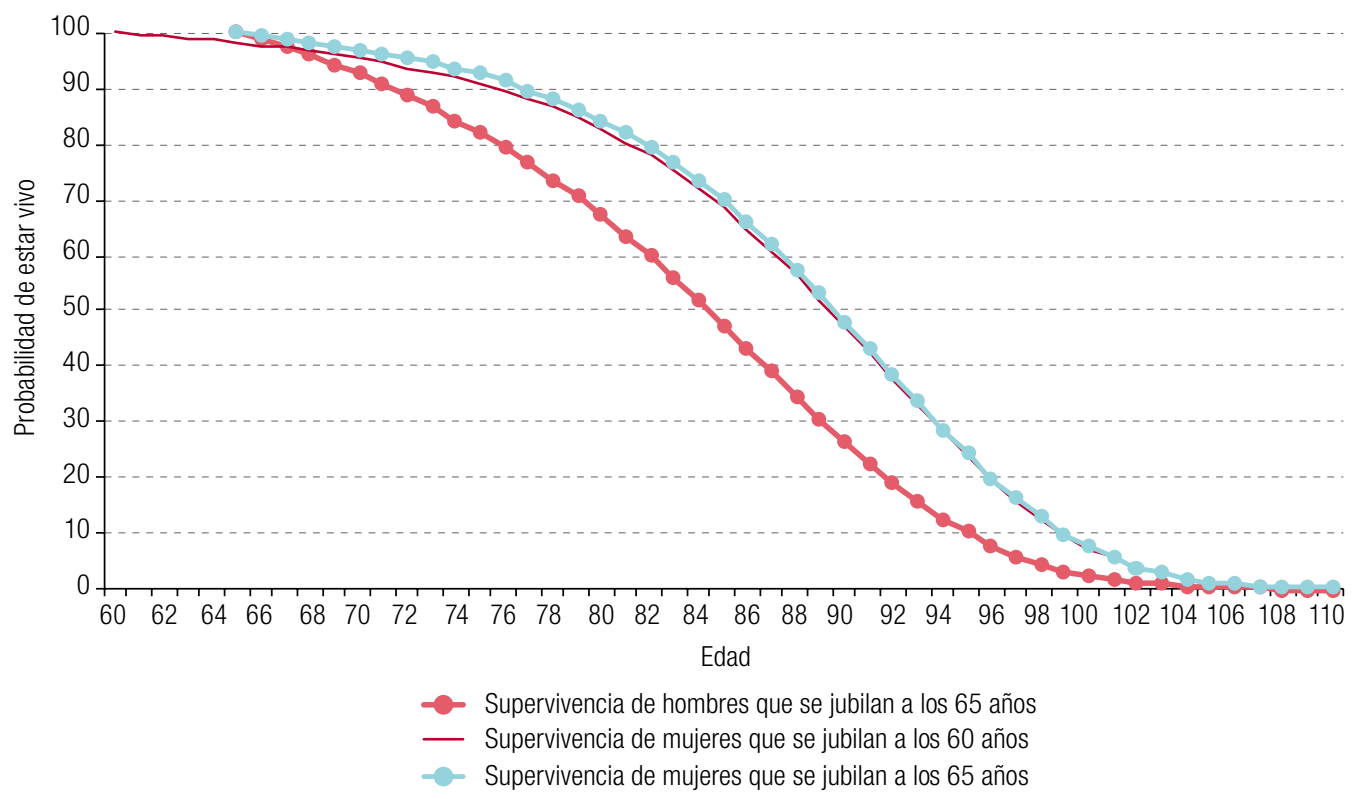

Fuente: Elaboración propia, sobre la base de Superintendencia de Pensiones de Chile, "Compendio de Normas del Sistema de Pensiones, Libro III, Título X, Tablas de Mortalidad, Anexo № 5”, Santiago, 2009 [en línea] http://www.spensiones.cl/ portal/compendio/596/w3-propertyvalue-4350.html. 


\section{Datos}

La Encuesta de Protección Social (EPS) es una encuesta longitudinal con representatividad a nivel poblacional que en su versión 2009 recoge observaciones de diversa índole sobre cerca de 16.000 hogares de todo Chile. La EPS ha sido fundamental para el análisis y diseño de políticas públicas en Chile ${ }^{9}$, específicamente en lo relacionado con las pensiones, por lo que resulta una fuente de información fundamental para nuestro estudio. A partir de ella, se extrajo una muestra en la que se conserva solo el grupo objetivo de la hipoteca inversa, es decir, los individuos propietarios de una vivienda en edad de jubilación (mujeres de 60 años o más, y hombres de 65 años o más).

Consecuentemente, a fin de obtener el precio de las viviendas al momento de tomar la encuesta se formula la siguiente pregunta: "Si vendiera hoy su casa, ¿cuánto cree que sería el valor de esta propiedad?"10. A la respuesta a esa pregunta llamaremos de ahora en adelante "precio de la vivienda". Sin embargo, al ser esta una apreciación personal, puede estar sesgada. Con el propósito de corregir este sesgo se asumirá que la movilidad de individuos entre regiones es baja, por lo que se segmentará a los individuos según la región donde nacieron y por deciles según factor de expansión, formando grupos homogéneos en cuanto al inmueble. Así bien, a cada individuo se le imputa como precio de su vivienda el promedio de la valoración de su segmento correspondiente. Esto resuelve el posible sesgo y, además, se recuperan las observaciones de los individuos que no saben o no responden cuando se les consulta por el precio de su vivienda. Por otro lado, en la muestra el valor de las viviendas no se distribuye en forma normal. Lo anterior se corrige recortando los datos de precios de vivienda sobre el percentil 97,5, que corresponde a precios de vivienda superiores a 100 millones de pesos. La distribución resultante queda representada por el gráfico 2. A su vez, el cuadro 1 incluye lo anterior y muestra la comparación entre las variables de precio de vivienda y precio de vivienda imputado, que corresponde al valor de la casa con los arreglos enunciados ya aplicados.

\section{Gráfico 2}

Distribución de precios de las viviendas en Chile

(En porcentajes)

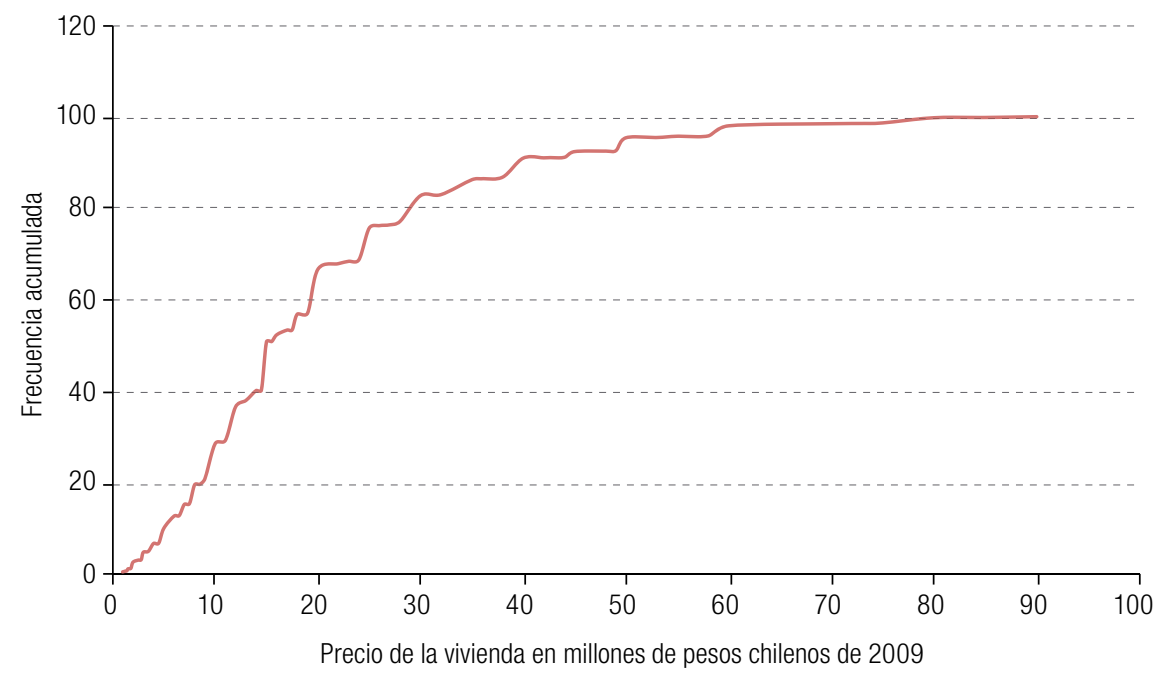

Fuente: Elaboración propia, sobre la base de la Encuesta de Protección Social, 2009.

\footnotetext{
9 A través de ella la Comisión Asesora Presidencial Sobre el Sistema de Pensiones (2015) detectó falencias en esta temática.

10 Esta pregunta corresponde a la consulta d17 de la EPS 2009.
} 
Cuadro 1

Comparación precio-vivienda y precio-vivienda imputado

\begin{tabular}{lccccc}
\hline Variable & Observaciones & Media & $\begin{array}{c}\text { Desviación } \\
\text { estándar }\end{array}$ & Mínimo & Máximo \\
\hline Precio vivienda (en millones de pesos de 2009) & 1752 & 20,60 & 15,00 & 1,00 & 90,00 \\
\hline Precio vivienda imputado (en millones de pesos de 2009) & 2627 & 20,40 & 4,11 & 2,50 & 50,00 \\
\hline
\end{tabular}

Fuente: Elaboración propia usando Encuesta de Protección Social 2009.

Nota: Cuadro elaborado en base a 2.627 observaciones que representan a una población de 1.623 .326 individuos.

Finalmente, de este proceso se conservaron 2.627 observaciones, que representan una población de 1.623 .326 hogares compuesta por un 59,1\% de mujeres y una edad promedio de 71 años. De los encuestados, el 65\% corresponde a jefes de hogar con un ingreso promedio por hogar de 103.749 pesos. Por otro lado, el promedio del ingreso per cápita resultó ser de 34.724 pesos (véase el cuadro del anexo A3) y, dado lo anterior, el $86,25 \%$ de las personas se encuentran bajo la línea de pobreza ${ }^{11}$.

\section{Sección empírica}

Para hacer una simulación de los pagos mensuales es preciso conocer el precio de las viviendas al momento de jubilarse y al terminar el contrato, el precio inicial de la vivienda imputado a 2009 en la EPS, siguiendo la modelación de Szymanoski (1994). Se advierte una media de 14 millones de pesos en el precio de los inmuebles al momento de la jubilación y una media levemente superior a 30 millones de pesos para la esperanza del valor de las propiedades al terminar el contrato (véase el cuadro 2). De lo anterior se puede obtener la relación préstamo-valor (RPV). Se observa que la media es del $59,42 \%$. Además, se puede subdividir este valor por género, donde la RPV para las mujeres es del $53,92 \%$ y para los hombres del $72,36 \%$. Las cifras anteriores concuerdan con el hecho de que la esperanza de la duración del contrato para los hombres es menor, debido a una mayor edad de jubilación y menor esperanza de vida que las mujeres.

Una vez obtenida la RPV podemos calcular el valor presente del préstamo (VPP), que se puede entender como una suma alzada que la institución financiera pagaría al dueño del inmueble al momento de contratar la hipoteca inversa, en vez de efectuar pagos mensuales. La media del VPP es de 8 millones de pesos, a partir de la cual se calculan los pagos mensuales suponiendo que todos los individuos aplicables contraten una hipoteca inversa, observando que la media de dichos pagos es de 62.508 pesos, con una desviación estándar de 29.760 pesos. Sin embargo, al considerar en la muestra a los pensionados autónomos ${ }^{12}$, la pensión promedio resulta ser igual a 145.808 pesos, valor que se vería incrementado en un $43 \%$ si incluyéramos los pagos por la hipoteca inversa. Ahora bien, si consideramos en la muestra a los pensionados bajo aporte solidario (no autónomo), la pensión promedio ascendió a 58.245 pesos, cifra que se vería incrementada en un 107\% si tuviéramos en cuenta los pagos de la hipoteca inversa. Estos incrementos tan grandes se explican por lo bajo de las pensiones en Chile, pero también ponen de manifiesto que las personas mayores poseen importantes volúmenes de riqueza ilíquida.

También procede hacer un análisis de los pagos de la hipoteca inversa según el género del pensionado, ya que este condiciona la edad de jubilación y la esperanza de vida, elementos que determinan la duración del contrato y el monto del préstamo al cual podrían acceder. Por otro lado,

\footnotetext{
${ }^{11}$ Línea de pobreza urbana en términos de situación de pobreza por ingresos (absoluta) para Chile (véase [en línea] http:// observatorio.ministeriodesarrollosocial.gob.cl/casen/casen_def_pobreza.php), que corresponde a 64.134 pesos per cápita.

12 Es decir, sin considerar aportes estatales. 1.093 (41\% de la muestra) observaciones presentan esta característica.
} 
el género también condiciona el monto de la pensión base, lo que a su vez define la base inicial de la riqueza, ya que las mujeres reciben en promedio una pensión de 51.174 pesos mientras que los hombres reciben en promedio 89.185 pesos (véase el cuadro 2). Ello se explica por diferencia en la participación laboral y por las brechas salariales entre mujeres y hombres existentes en Chile (Sáez, 2010).

Cuadro 2

Estimación de los parámetros de la hipoteca inversa

\begin{tabular}{lcrrrr}
\hline Variable & Observaciones & Media & $\begin{array}{c}\text { Desviación } \\
\text { estándar }\end{array}$ & Mínimo & Máximo \\
\hline Precio de la vivienda al jubilarse (en millones de pesos de 2009) & 2627 & 14,00 & 5,40 & 1,12 & 47,80 \\
\hline $\begin{array}{l}\text { Precio de la vivienda al término del contrato } \\
\text { (en millones de pesos de 2009) }\end{array}$ & 2627 & 31,6 & 13,60 & 1,83 & 122,00 \\
\hline Relación préstamo-valor (en porcentajes) & 2627 & 59,42 & 8,44 & 53,92 & 72,36 \\
\hline Valor presente del préstamo (en millones de pesos de 2009) & 2627 & 8,07 & 3,43 & 0,79 & 33,10 \\
\hline Pagos mensuales (en pesos) & 2627 & 62508 & 29760 & 6807 & 285512 \\
\hline Pagos mensuales de las mujeres (en pesos) & 1552 & 51174 & 20539 & 7883 & 178732 \\
\hline Pagos mensuales de los hombres (en pesos) & 1075 & 89158 & 31053 & 6807 & 285512 \\
\hline
\end{tabular}

Fuente: Elaboración propia usando Encuesta de Protección Social 2009.

Nota: Cuadro elaborado en base a 2.627 observaciones que representan a una población de 1.623.326 individuos.

Como hemos señalado, la edad de jubilación es distinta entre mujeres y hombres, con una diferencia de cinco años, lo cual afecta la forma en que se desempeñará el contrato de la hipoteca inversa, ya que condiciona su duración. Actualmente en Chile las mujeres se jubilan a los 60 años de edad, lo que estudiaremos como el escenario estándar, aunque también hemos analizado un escenario alternativo en el que las mujeres se jubilan a la misma edad que los hombres (65 años). Tal y como se esperaba, al aumentar las edad de jubilación de las mujeres, el pago mensual de la hipoteca inversa aumenta en un 55\% (28.221 pesos); además, se reduce la brecha por género en un $74,3 \%$, tal como se puede apreciar en el cuadro 3. Por lo tanto, en igualdad de condiciones financieras existirá igualdad en el monto recibido por concepto de hipoteca inversa; si se desea utilizar este instrumento en el diseño de una política pública, esto ha de tomarse en cuenta.

Cuadro 3

Análisis de pagos mensuales según sexo y edad de jubilación

(En pesos chilenos)

\begin{tabular}{lccccc}
\hline Situación & $\begin{array}{c}\text { Edad de jubilación } \\
\text { mujeres }\end{array}$ & $\begin{array}{c}\text { Edad de jubilación } \\
\text { hombres }\end{array}$ & $\begin{array}{c}\text { Pagos mensuales } \\
\text { Total }\end{array}$ & $\begin{array}{c}\text { Pagos mensuales } \\
\text { mujeres }\end{array}$ & $\begin{array}{c}\text { Pagos mensuales } \\
\text { hombres }\end{array}$ \\
\hline Escenario estándar & 60 & 65 & 62508 & 51174 & 89158 \\
\hline Escenario alternativo & 65 & 65 & 82308 & 79395 & 89158 \\
\hline Variación & & & 19800 & 28221 & 0 \\
\hline
\end{tabular}

Fuente: Elaboración propia, sobre la base de la Encuesta de Protección Social, 2009.

Nota: Cuadro elaborado en base a 2.627 observaciones que representan a una población de 1.623.326 individuos.

Tomando los resultados anteriores sobre el escenario estándar, resulta útil agregar los pagos mensuales por concepto de este instrumento al ingreso familiar. La hipoteca inversa tiene la capacidad de aumentar, en promedio, cerca de un 60\% el ingreso del hogar del grupo objetivo, que pasaría de 103.749 pesos a 166.258 pesos. Consecuentemente, también se aumenta el ingreso per cápita en aproximadamente un 57\%, pasando de 34.724 pesos a 54.537 pesos, tal y como se observa en el cuadro 4. Esto no tiene solo connotación en la distribución de la riqueza, sino también en el aumento en la calidad de vida de estos hogares, debido a los mayores niveles de utilidad. 
Cuadro 4

Incidencia de la hipoteca inversa sobre el ingreso (escenario estándar) (En pesos chilenos)

\begin{tabular}{lcccr}
\hline Variable & Media & Desviación estándar & Mínimo & Máximo \\
\hline Ingreso del hogar sin contratar hipoteca inversa & 103749 & 136576 & 0 & 2000000 \\
\hline Ingreso del hogar contratando hipoteca inversa & 166258 & 141879 & 7883 & 2121002 \\
\hline Media variación del ingreso del hogar & $60,25 \%$ & & & \\
\hline Ingreso per cápita sin contratar hipoteca inversa & 34724 & 49533 & 0 & 450000 \\
\hline Ingreso per cápita contratando hipoteca inversa & 54537 & 57525 & 2037 & 519441 \\
\hline Media variación del ingreso per cápita & $57,06 \%$ & & & \\
\hline
\end{tabular}

Fuente: Elaboración propia usando EPS 2009.

Nota: Cuadro elaborado en base a 2.627 observaciones que representan a una población de 1.623 .326 individuos.

Tras haber simulado los pagos mensuales y suponiendo que todos los individuos que están en condiciones de hacerlo contratan una hipoteca inversa, es posible analizar qué consecuencias tiene esto sobre la pobreza en la muestra. Se observa que la contratación de este instrumento provocaría una reducción del 15\% en el índice de pobreza para toda la muestra (véase el cuadro 5).

Cuadro 5

Efecto potencial de la hipoteca inversa sobre la pobreza (escenario estándar)

(En porcentajes, salvo la columna de cifras de la izquierda)

\begin{tabular}{lcccc}
\hline \multirow{2}{*}{ Variable } & \multirow{2}{*}{ Observaciones } & \multicolumn{2}{c}{ Índice de pobreza } & Reducción porcentual \\
\cline { 3 - 4 } & 2627 & Sin hipoteca inversa & Con hipoteca inversa & de la pobreza \\
\hline Total & 434 & 86,25 & 73,17 & 15,17 \\
\hline $\begin{array}{l}\text { Cotizantes a Administradoras de } \\
\text { Fondos de Pensiones (AFP) }\end{array}$ & 1935 & 90,71 & 83,77 & 7,65 \\
\hline Encuestado es jefe del hogar & 692 & 81,30 & 65,24 & 19,75 \\
\hline Encuestado no es jefe del hogar & 1552 & 95,48 & 87,95 & 7,89 \\
\hline Mujeres & 1075 & 88,40 & 79,64 & 9,91 \\
\hline Hombres & & 81,18 & 57,94 & 28,63 \\
\hline
\end{tabular}

Fuente: Elaboración propia sobre la base de la Encuesta de Protección Social, 2009.

Nota: Cuadro elaborado en base a 2.627 observaciones que representan a una población de 1.623 .326 individuos.

En este sentido, el efecto potencial es bajo en comparación con los estudios realizados en los Estados Unidos (Mayer y Simons, 1994; Kutty, 1998), España y Bélgica (Moscarola y otros, 2015), aunque mayor que el detectado en el Reino Unido (Hancock, 1998), Dinamarca, Alemania, Holanda, Austria y Suecia (Moscarola y otros, 2015). La reducción de la pobreza que mostró nuestra simulación se encuentra entre los niveles alcanzados para Italia y Francia (Moscarola y otros, 2015), tal como se observa en el cuadro 6 . Esto nos indica que nuestro modelo de simulación es confiable, ya que la predicción de la reducción de la pobreza está dentro de los rangos definidos en la literatura especializada, lo que también confirma la veracidad de los parámetros económicos establecidos. 


\section{Cuadro 6}

Efecto potencial de la hipoteca inversa sobre la pobreza en distintos países (En porcentajes)

\begin{tabular}{lccl}
\hline País & Porcentaje de reducción de pobreza & Año de los datos & Autor \\
\hline Suecia & 3 & 2012 & Moscarola y otros, 2015 \\
\hline Reino Unido & 4 & 1995 & Hancock, 1998 \\
\hline Austria & 4 & 2012 & Moscarola y otros, 2015 \\
\hline Holanda & 5 & 2012 & Moscarola y otros, 2015 \\
\hline Alemania & 6 & 2012 & Moscarola y otros, 2015 \\
\hline Dinamarca & 8 & 2012 & Moscarola y otros, 2015 \\
\hline Francia & 14 & 2012 & Moscarola y otros, 2015 \\
\hline Italia & 16 & 2012 & Moscarola y otros, 2015 \\
\hline Bélgica & 25 & 2012 & Moscarola y otros, 2015 \\
\hline España & 27 & 2012 & Moscarola y otros, 2015 \\
\hline Estados Unidos & 29 & 1991 & Kutty, 1998 \\
\hline Estados Unidos & 74 & 1990 & Mayer y Simons, 1994 \\
\hline
\end{tabular}

Fuente: Elaboración propia.

a Los valores corresponden a la cota superior para cada país descrito en el documento.

Si se considera solamente a las personas pertenecientes al sistema de AFP, la reducción de pobreza es del 7,65\%, mucho menor que en el total de la muestra. Ello se debe a que, pese a que los cotizantes de AFP recibirían pagos mensuales por un valor un $20 \%$ mayor que el promedio de la muestra, sus ingresos iniciales son cerca de dos tercios de la media del total (véase el cuadro 5). Con respecto al jefe del hogar, la incidencia del instrumento en términos de reducción de pobreza es mayor a la media muestral y levemente más que el doble comparado con aquellos que no lo son, por lo que el impacto sería menor al inicialmente determinado, comparable al de Dinamarca y Alemania (Moscarola y otros, 2015). Aunque reducido, igual supone un impacto positivo en un poco más de 100.000 hogares.

Por último, es posible aislar el indicador con respecto al género. En mujeres la pobreza inicial es casi un 10\% mayor, dado ingresos per cápita 50\% más altos en hombres. Así bien, como se mostró en el cuadro 3, en el escenario estándar las mujeres reciben pagos ampliamente menores al de sus pares hombres por concepto de hipoteca inversa, a raíz de lo cual la reducción de pobreza es del $9,91 \%$, a diferencia del $28,63 \%$ en los hombres. Por lo tanto, si sumamos la hipoteca inversa a la decisión de jubilarse, se hace importante igualar las condiciones financieras por género, porque aunque su aporte mejorará el bienestar de las personas jubiladas y sus hogares, también podría acentuar las brechas en riqueza derivadas del género.

Al aumentar la edad de jubilación de las mujeres, el potencial social de este instrumento en ellas conlleva una reducción del $5,31 \%$, cifra superior a la situación estándar pero que continúa siendo menor al potencial del género masculino. Consecuentemente, la reducción porcentual de la pobreza en toda la muestra se amplía un 3,81\%. 


\section{Cuadro 7}

Potencial de la hipoteca inversa sobre la pobreza según el sexo y la edad de jubilación (En porcentajes en las tres columnas de la derecha)

\begin{tabular}{lccccc}
\hline Situación & $\begin{array}{c}\text { Edad de jubilación } \\
\text { de mujeres }\end{array}$ & $\begin{array}{c}\text { Edad de jubilación } \\
\text { de hombres }\end{array}$ & $\begin{array}{c}\text { Reducción porcentual } \\
\text { de la pobreza total }\end{array}$ & $\begin{array}{c}\text { Reducción porcentual } \\
\text { de la pobreza } \\
\text { de mujeres }\end{array}$ & $\begin{array}{c}\text { Reducción porcentual } \\
\text { de la pobreza } \\
\text { de hombres }\end{array}$ \\
\hline Escenario estándar & 60 & 65 & 15,17 & 9,91 & 28,63 \\
\hline Escenario alternativo & 65 & 65 & 18,98 & 15,22 & 28,63 \\
\hline Variación & & & 3,81 & 5,31 & 0,00 \\
\hline
\end{tabular}

Fuente: Elaboración propia sobre la base de la Encuesta de Protección Social 2009.

Nota: Cuadro elaborado en base a 2.627 observaciones que representan a una población de 1.623 .326 individuos.

Los resultados de nuestra simulación pueden parecer auspiciosos, pero se debe tener en cuenta que a ellos se llega suponiendo que todas las personas que pueden hacerlo contratan la hipoteca inversa, lo cual parece poco realista. En efecto, los resultados previstos en reducción de la pobreza a raíz de este instrumento no son los esperados. Davidoff, Gerhard y Post (2017) y Nakajima y Telyukova (2017) sostienen que solo el 1,7\% de los individuos con posibilidades de hacerlo en los Estados Unidos efectivamente contratan una hipoteca inversa, identificando además la participación en el instrumento de personas que están solas, tienen ingresos bajos, con mala salud y dueñas de propiedades más caras que el promedio. De esta manera, si nos concentramos solo en este grupo, es decir, el más participativo, en el presente estudio la reducción de pobreza sería cercana al 2\%. Ello se debe a que en dicho segmento los individuos son inicialmente tan pobres que los pagos mensuales no dan lugar a la superación de ese índice de vulnerabilidad para gran parte de estos contratantes, aunque sí aumentan su liquidez y, por ende, su nivel de bienestar. Sin embargo, se debe tener en cuenta que nuestros cálculos se limitan a las condiciones que observamos en el presente y, no lo que podrían darse en el futuro, como ingresos futuros, redes de apoyo familiar o potenciales subsidios.

\section{Análisis por tramo etario}

Nuestro análisis precedente parte del supuesto de que los individuos contratan la hipoteca inversa al momento de jubilarse, pero ellos pueden hacerlo cuando lo deseen a partir de la fecha de jubilación. Cabe señalar que a medida que aumenta la edad de la persona que celebra el contrato se producen efectos que inciden en los pagos mensuales. En primer lugar, contratar una hipoteca inversa a mayor edad disminuye la esperanza del número de períodos en que se efectúan los pagos, acrecentándolos. Esto, a su vez, reduce el descuento que se realiza en la relación préstamo-valor (RPV), aumentándola a medida que los individuos presentan un menor riesgo para el prestamista. Ambas consecuencias dan lugar a un alza en los pagos mensuales. Sin embargo, ello se ve contrarrestado por una menor apreciación de la propiedad, disminuyendo así la RPV.

Por su parte, en la literatura especializada se presenta una relación positiva entre la edad en que se contrata el instrumento y los pagos mensuales (Ma y Deng, 2013). El propósito de este apartado consiste entonces en simular cómo variarían los pagos mensuales a medida que un individuo representativo de distintos tramos etarios contrata una hipoteca inversa en Chile. Para ello se utiliza una tabla de mortalidad conjunta que no diferencia por género, que se detalla en el cuadro 11 del anexo 2.

Se presentan dos casos: en el primero (véase el cuadro 8 y el anexo) se considera que el precio de la vivienda al iniciar el contrato es el promedio de los precios de inmuebles al momento de jubilarse los individuos de la muestra, es decir 14 millones de pesos de 2009. En efecto, se analiza cómo variarían los pagos mensuales si un individuo representativo con este valor de inmueble contratara la hipoteca inversa a las edades de 65, 70, 75 y 80 años (véase el cuadro 8). 
Cuadro 8

Caso 1: análisis de la hipoteca inversa por tramo etario

\begin{tabular}{lrrrr}
\hline \multicolumn{7}{c}{ Precio del inmueble imputado de 14 millones de pesos de 2009 } & & & \\
\hline Edad al contratar hipoteca inversa & 65 & 70 & 75 & 80 \\
\hline Precio del inmueble imputado (en millones de pesos de 2009) & 14,00 & 14,00 & 14,00 & 14,00 \\
\hline Esperanza precio del inmueble al vencer el contrato (en millones de pesos de 2009) & 32,70 & 26,10 & 21,00 & 16,80 \\
\hline Relación préstamo-valor (en porcentajes) & 57,9 & 66,25 & 77,19 & 89,36 \\
\hline Valor presente del préstamo (en millones de pesos de 2009) & 7,73 & 8,99 & 10,50 & 12,20 \\
\hline Pagos mensuales (en pesos) & 62387 & 80179 & 107080 & 149793 \\
\hline
\end{tabular}

Fuente: Elaboración propia usando Encuesta de Protección Social 2009.

A medida que aumenta la edad de contratación disminuye el valor esperado del precio del inmueble al vencer el contrato, mientras que se amplía la RPV. Es decir, domina el efecto al alza sobre esta última variable. En vista de lo anterior, aumenta el valor presente del préstamo, el cual se ve potenciado por el menor número de períodos en que está vigente el contrato, incrementando así los pagos mensuales a tasas crecientes. Ello se aprecia claramente en el gráfico 3: los pagos mensuales, medios y marginales están en relación positiva con la edad de contratación. Un individuo representativo obtendría pagos mensuales periódicos de 62.387 pesos al contratar una hipoteca inversa a los 65 años, lo cual iría aumentando progresivamente hasta llegar a 149.796 pesos si opta por el instrumento a los 80 años. En el anexo A4 figuran más detalles acerca de los pagos.

Gráfico 3

Caso 1: pagos mensuales

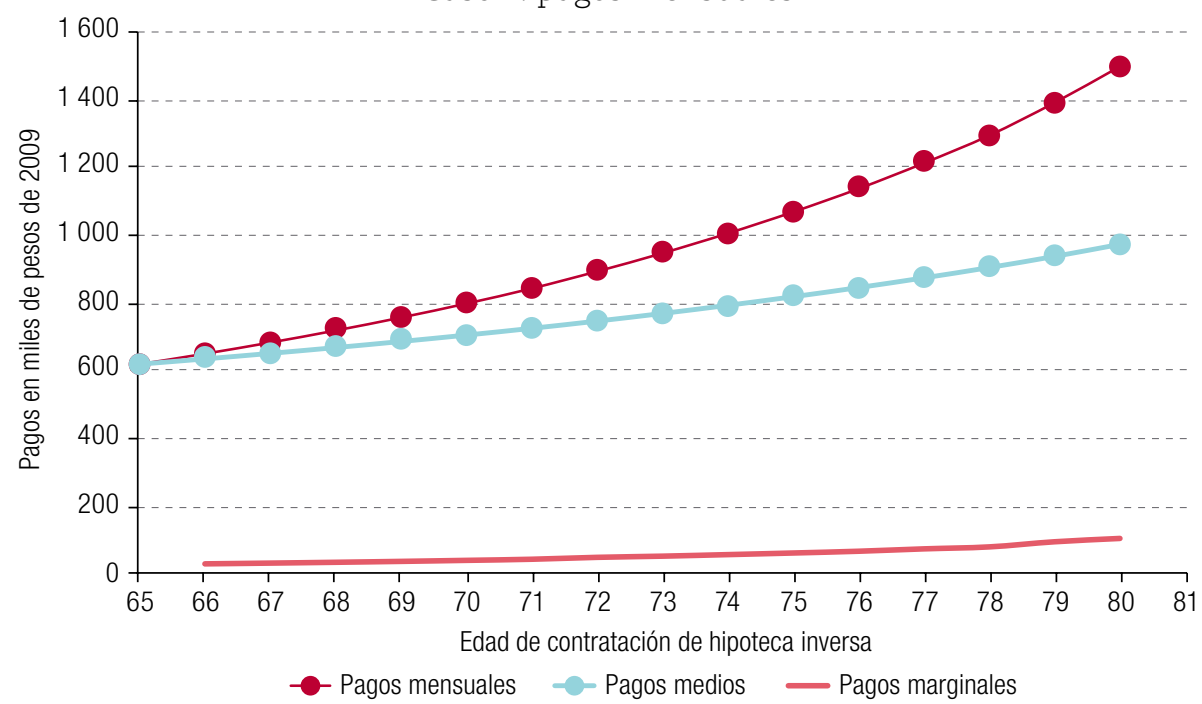

Fuente: Elaboración propia, sobre la base de la Encuesta de Protección Social, 2009

Por su parte, en el segundo caso (véase el cuadro 9 y el anexo) se sigue el procedimiento anterior, pero se considera que el precio inicial de la vivienda corresponde al promedio de los precios de inmuebles imputados a 2009, lo que equivale a 20,04 millones de pesos, manteniendo la relación préstamo valor en cada edad y las tasas de aumento de los pagos mensuales. En concreto, un individuo que se jubile a los 65 años obtendría otros 90.907 pesos mensuales por concepto de hipoteca inversa, cifra que iría en aumento hasta llegar a los 218.270 pesos si contrata la hipoteca inversa a los 80 años (véase el anexo A4). Entonces, al implementar este instrumento se observará dispersión en los pagos otorgados, debido a la distribución de la edad en que se realice el contrato. También incidirá la distribución del precio del inmueble, el cual dependerá de su futura plusvalía. 
Cuadro 9

Caso 2: análisis de hipoteca inversa por tramo etario

\begin{tabular}{lrrrr}
\hline \multicolumn{7}{c}{ Precio del inmueble imputado de 20,04 millones de pesos de 2009 } & & \\
\hline Edad al contratar hipoteca inversa & 65 & 70 & 75 & 80 \\
\hline Precio del inmueble imputado (en millones de pesos de 2009) & 20,04 & 20,04 & 20,04 & 20,04 \\
\hline Esperanza precio del inmueble al terminar el contrato (en millones de pesos de 2009) & 47,60 & 38,01 & 30,60 & 24,50 \\
\hline Relación préstamo-valor (en porcentajes) & 57,19 & 66,25 & 77,19 & 89,36 \\
\hline Valor presente del préstamo (en millones de pesos de 2009) & 11,30 & 13,10 & 15,3 & 17,80 \\
\hline Pagos mensuales (en pesos) & 90907 & 116832 & 156031 & 218270 \\
\hline
\end{tabular}

Fuente: Elaboración propia, sobre la base de la Encuesta de Protección Social, 2009.

Gráfico 4

Caso 2: pagos mensuales

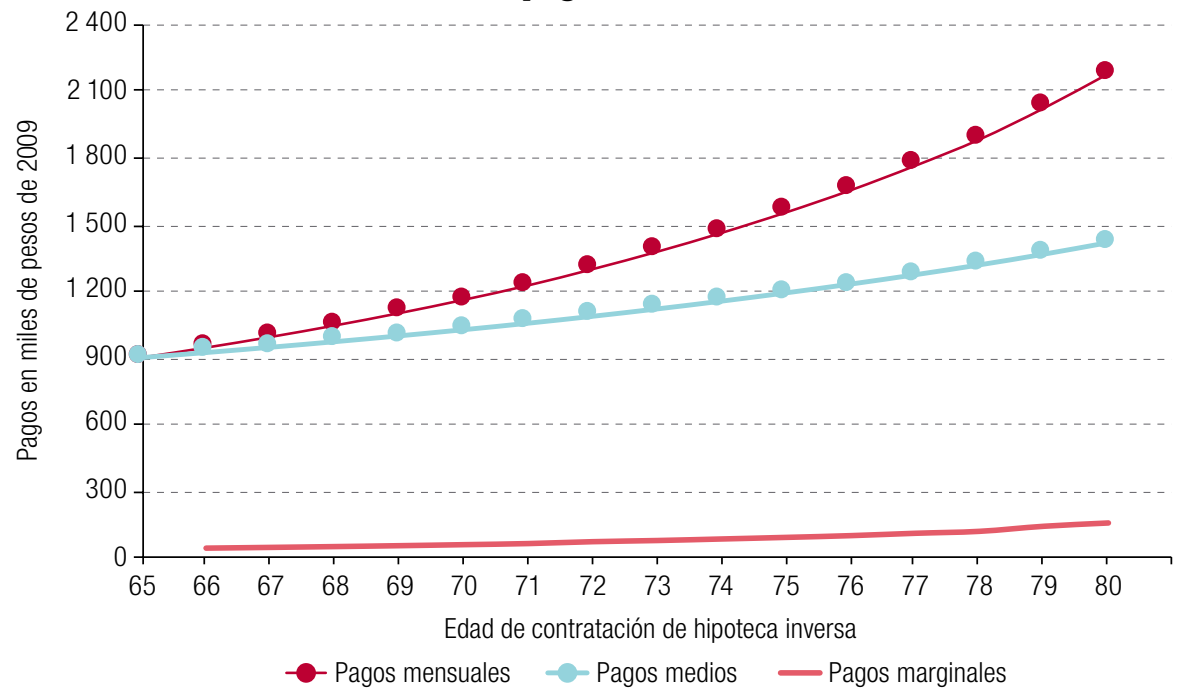

Fuente: Elaboración propia, sobre la base de la Encuesta de Protección Social, 2009.

\section{Conclusiones}

Nuestro estudio simuló el potencial social y económico de implementar la hipoteca inversa al grupo de pensionados en Chile. Utilizamos la metodología propuesta por Ma y Deng (2013) y Wang y Kim (2014), con algunas innovaciones como el uso de tablas de mortalidad de Chile, además de información del precio de las viviendas extraídas de la Encuesta de Protección Social, 2009, debido a su representatividad a nivel poblacional y carácter previsional. La muestra utilizada abarca a 1.623 .326 pensionados, que representan aproximadamente el 9\% de la población adulta en Chile (Superintendencia de Pensiones, 2009a). Implementar la hipoteca inversa no resuelve todos los problemas de ingreso que enfrentan las personas mayores en Chile, pero sí puede ayudar a aquellos que poseen una vivienda y que pueden utilizarla como colateral, a fin de mejorar su independencia económica al recuperar parte de un riqueza ilíquida.

Llegamos a la conclusión de que el aumento de liquidez a raíz de la contratación de una hipoteca inversa reduce el porcentaje de la población mayor de edad que se encuentra en situación de pobreza. En el caso de que todos los potenciales usuarios contraten una hipoteca inversa el índice de pobreza se reduciría en un 15\%, pero al restringir la muestra a las personas que pertenecen 
al sistema de pensiones vigente (capitalización individual), el índice de pobreza se reduce en un $7,65 \%$. Sin embargo, si nos limitamos a las características de los que han participado en donde se ha implementado la hipoteca inversa (Davidoff y otros, 2017; Nakajima y Telyukova, 2017) como estar solo, tener bajos ingresos, tener mala salud y con un valor de la propiedad más alto que el promedio, el índice de pobreza se ve reducido un $2 \%$. Estos resultados se ajustan a los rangos que presenta la literatura especializada, confirmando así la confiabilidad de nuestros hallazgos, aunque solo a nivel tendencial, porque los eventos aleatorios son incompatibles con la capacidad predictiva que buscamos.

Nuestros hallazgos indican que al implementar la hipoteca inversa al momento de jubilarse los individuos podrían usar en promedio un 59\% de su propiedad como colateral, obteniendo pagos mensuales constantes de 62.508 pesos, lo que equivale a un 60\% del ingreso promedio de los hogares con personas jubiladas. A su vez, lo anterior representa un aumento del 57\% en el ingreso per cápita del contratante. Por otro lado, los pagos mensuales presentan una brecha cuando se hace el análisis por género, de forma que las mujeres reciben un 42,6\% (37.984 pesos) menos que los hombres. Tal diferencia proviene de la mayor esperanza de vida y menor edad de jubilación de las mujeres, lo que aumenta la duración de sus contratos. No obstante, si se incrementa la edad de jubilación de las mujeres a los 65 años, la brecha por género se reduce a un 10,9\% (9.763 pesos). Esto nos indica que de implementar este instrumento a través de políticas públicas, se debe considerar el igualar las condiciones financieras por género; de lo contrario, aunque su aporte mejorará el bienestar de las personas jubiladas y de sus hogares, también podría acentuar las brechas en riqueza por género.

Desde otro punto de vista, nuestras simulaciones nos permitieron analizar de qué manera variarían los pagos mensuales en relación a la edad en que se contrata la hipoteca inversa. Un individuo que contrata el instrumento a los 65 años de edad podría utilizar un 57\% de su propiedad como colateral, pero si lo hace a los 80 años de edad ese porcentaje subiría a un 89\%, lo que pone de manifiesto una relación a tasa creciente entre el monto recibido por hipoteca inversa y la edad a la que se realice dicho contrato. Entonces, al implementar este instrumento, dentro de un contexto de políticas públicas se debe tener en cuenta la dispersión que se obtendrá en los pagos otorgados por este instrumento, debido a la distribución de la edad en que se realice el contrato. También existirá dispersión por la distribución del precio del inmueble, el cual dependerá de su futura plusvalía. Estos elementos le dan diversidad al instrumento financiero, por lo que podría existir más de un tipo de institución financiera interesada en otorgar estos contratos.

En resumen, los resultados que se presentaron en este estudio muestran que la hipoteca inversa es un instrumento útil para el aumento de liquidez en los pensionados. Lo anterior es importante en un contexto donde el $70 \%$ de los chilenos sostiene que las pensiones son insuficientes para mantener un nivel de vida adecuado en la vejez. Más aún, se detalla el relevante potencial social de reducción de la pobreza, lo cual generaría indiscutibles mejoras de bienestar para el grupo objetivo. Lo que prima en la implementación de la hipoteca inversa es que las personas mayores tengan acceso al crédito y así aumentar sus ingresos, sin perjudicar su situación económica actual. No obstante, se debe considerar a los herederos del deudor, ya que este instrumento es una hipoteca y no implica una transferencia del dominio. Esto podría generar un conflicto de intereses entre ambos, requiriéndose de una legislación que brinde herramientas necesarias para proteger tanto a herederos como acreedores (Fuentes y Moris, 2014). 


\section{Bibliografía}

Alonso, J., D. Tuesta y M. Lamuedra (2013), "Potencialidad del desarrollo de hipotecas inversas como complemento pensionario: el caso de Chile", Documento de Trabajo, Nㅜ 9, Madrid, Banco Bilbao Vizcaya Argentaria (BBVA).

Banco Central de Chile (2017), "Base de datos estadísticos. Indicadores sectoriales" [en línea] https://si3. bcentral.cl/Siete/secure/cuadros/arboles.aspx.

Bartel, H. y M. Daly (1980), "Reverse annuity mortgages as a source of retirement income", Canadian Public Policy/Analyse de Politiques, vol. 6, No 4, Toronto, University of Toronto Press.

Comisión Asesora Presidencial sobre el Sistema de Pensiones (2015), Informe final, Santiago [en línea] http:// www.comision-pensiones.cl/Informe_final_CP_2015.pdf.

Davidoff, T. (2010), "Interest accumulation in retirement home equity products", Working Paper, Vancouver, University of British Columbia.

Davidoff, T., P. Gerhard y T. Post (2017), “Reverse mortgages: what homeowners (don't) know and how it matters", Journal of Economic Behavior \& Organization, vol. 133, Amsterdam, Elsevier.

Fornero, E., M. Rossi y M. Urzi (2016), "Explaining why, right or wrong, (Italian) households do not like reverse mortgages", Journal of Pension Economics \& Finance, vol. 15, Nㅜㄹ, Cambridge, Cambridge University Press.

Fuentes, M. y D. Moris (2014), "El futuro de la hipoteca inversa en Chile", tesis para optar al grado de licenciado, Santiago, Universidad de Chile.

Hancock, R. (1998), "Can housing wealth alleviate poverty among Britain's older population?", Fiscal Studies, vol. 19, № 3, Hoboken, Wiley.

INE (Instituto Nacional de Estadísticas) (2010a), Boletín informativo. Enfoque estadístico hombres y mujeres en Chile, Santiago. (2010b), Compendio estadístico año 2010, Santiago.

INE/CEPAL (Instituto Nacional de Estadísticas/Comisión Económica para América Latina y el Caribe) (s/f), Estimaciones y proyecciones de población por sexo y edad. Total país 1950-2050, Santiago.

Kutty, N. (1998), "The scope for poverty alleviation among elderly home-owners in the United States through reverse mortgages", Urban Studies, vol. 35, № 1, Thousand Oaks, Sage.

Ma, S. y Deng (2013), "Evaluation of reverse mortgage programs in Korea", Seoul Journal of Business, vol. 19, № 1, Seúl, Universidad Nacional de Seúl.

Mayer, C. y K. Simons (1994), "Reverse mortgages and the liquidity of housing wealth", Real Estate Economics, vol. 22, № 2, Hoboken, Wiley.

Moscarola, F. y otros (2015), "Reverse mortgage: a tool to reduce old age poverty without sacrificing social inclusion", Ageing in Europe - Supporting Policies for an Inclusive Society, A. Börsch-Supan y otros (eds.), Berlín, Walter De Gruyter.

Moulton, S. y otros (2015), "Who gets a reverse mortgage? Identifying household level determinants of U.S. reverse mortgage choices", ponencia presentada en la XXII Conferencia Anual de la European Real Estate Society (ERES), Estambul, 24 a 27 de junio.

Muñoz, M. (2011), "Hipoteca revertida en Chile: una alternativa para la reducción de la pobreza", tesis para optar al grado de magister, Santiago, Universidad de Chile.

Nakajima, M. e I. Telyukova (2017), "Reverse mortgage loans: a quantitative analysis", The Journal of Finance, vol. 72, № 2, Hoboken, Wiley.

OCDE (Organización de Cooperación y Desarrollo Económicos) (2013), Pensions at a Glance 2013. OECD and G20 Indicators, París.

Ong, R. (2008), "Unlocking housing equity through reverse mortgages: the case of elderly homeowners in Australia", European Journal of Housing Policy, vol. 8, No 1, Abingdon, Taylor \& Francis.

Phillips, W. y S. Gwin (1993), "Reverse mortgages", Transactions of the Society of Actuaries, № 44, Schaumburg, Society of Actuaries .

Rodda, D., C. Herbert y H. Lam (2000), Evaluation Report of FHA's Home Equity Conversion Mortgage Insurance Demonstration, Abt Associates Inc., marzo.

Rodda, D. y otros (2003), Refinancing Premium, National Loan Limit, and Long-Term Care Premium Waiver for FHA's HECM Program, Cambridge, U.S. Department of Housing and Urban Development.

Sáez, R. (2010), "La OCDE y el ingreso de Chile", Estudios Internacionales, vol. 43, № 166, Santiago, Universidad de Chile. 
Superintendencia de Pensiones (2010), El sistema de pensiones en Chile, Santiago.

_ (2009a), "Compendio de normas del sistema de pensiones, Libro III, Título X, Tablas de mortalidad" [en línea] http://www.spensiones.cl/portal/compendio/596/w3-propertyvalue-4350.html.

_ (2009b), "Compendio de Normas del Sistema de Pensiones, Libro III, Título X, Tablas de Mortalidad, Anexo № 5", Santiago [en línea] http://www.spensiones.cl/portal/compendio/596/w3-propertyvalue-4350.html. _ (2006), El sistema de pensiones en Chile, Santiago.

Szymanoski, E. (1994), "Risk and the home equity conversionmortgage", Real Estate Economics, vol. 22, № 2, Hoboken, Wiley.

The Economist (2016), "The perils of not saving", Londres, 27 de agosto.

Wang, P. y J. Kim (2014), "The value of reverse mortgage loans: case study of the Chinese market", Journal of Asian Finance, Economics and Business, vol. 1, № 4, Korea Distribution Science Association. 


\section{Anexo A1}

\section{Modelamiento del precio de las viviendas en distintos períodos}

Para realizar el modelamiento del presente estudio es preciso conocer el precio de las viviendas en períodos distintos al de la toma de la muestra. En concreto, debemos estimar el precio de estas al momento en que vencería el contrato (período posterior a la muestra) y, a su vez, el precio de los inmuebles cuando la persona se jubiló (período anterior a la muestra). Para realizar esto se seguirá el modelo de Szymanoski (1994), el cual se detalla a continuación.

Definimos las siguientes variables:

$$
\begin{gathered}
H_{t}: \text { Precio de la vivienda en el año } t \\
H_{0}: \text { Precio de la vivienda en el año } t=0 \text { inicial }
\end{gathered}
$$

Luego, se tiene que el porcentaje que representa $H_{t}$ con respecto a $H_{0}$ es $X_{t}$ :

A su vez:

$$
X_{t}=\frac{H_{t}}{H_{0}}
$$

$x$ : Variable aleatoria del set de observaciones $X_{t}$

Aplicando logaritmo natural a $X_{t}$ obtenemos el cambio porcentual del precio de la vivienda entre el periodo inicial y " $t$ " arbitrario:

$$
Y_{t}=\ln \left(X_{t}\right) \rightarrow X_{t}=\exp \left(Y_{t}\right)
$$

Donde:

$$
\text { y: Variable aleatoria del set de observaciones } Y_{t}
$$

En este sentido, usando la función exponencial $g(a)=\exp (a)$ tenemos:

$$
g(y)=\exp (y) \rightarrow E(x)=E(\exp (y))=E(g(Y))
$$

En este punto, Szymanoski (1994) sostiene que las tendencias de los precios de viviendas a largo plazo pueden ser modeladas por un proceso de Movimiento Browniano Geométrico (MBG). Consecuentemente se asume que $Y_{t}$ es un MBG, lo cual implica que en el periodo " $t$ ", $Y_{t}$ tiene una media de $\mu \cdot t$ y una desviación estándar de $\sqrt[\sigma]{t}$, describiendo una distribución normal. A su vez, con lo anterior $X_{t}$ queda definido como un MBG con una distribución log-normal.

Consecuentemente, sabemos que, dado $F(y)$ función de probabilidad de " $y$ " y $f(y)$ función de densidad de " $y$ ". De esta manera:

$$
E(g(y))=\int_{-\infty}^{+\infty} g(y) d F(y)=\int_{-\infty}^{+\infty} g(y) f(y) d y
$$


Como se argumentó, la variable " $y$ " sigue una distribución normal, por lo que $f(y)$ es una distribución de densidad normalmente distribuida con media $\mu$ y desviación estándar $\sigma$.

$$
f(y)=\frac{1}{\sigma \sqrt{2 \pi}} \exp \left[-\frac{1}{2}\left(\frac{y-\mu}{\sigma}\right)^{2}\right]
$$

Reemplazando (II) en (I):

$$
E(g(y))=E(\exp (y))=\frac{1}{\sigma \sqrt{2 \pi}} \int_{-\infty}^{+\infty} \exp (y) \cdot \exp \left[-\frac{1}{2}\left(\frac{y-\mu}{\sigma}\right)^{2}\right] d y
$$

Estandarizando lo anterior se reemplaza " $y$ " por $(y-\mu) / \sigma$, lo que da el siguiente resultado:

$$
E(\exp (y))=\exp \left(\mu+0,5 \sigma^{2}\right) \cdot\left(\frac{1}{\sqrt{2 \pi}}\right) \int_{-\infty}^{+\infty} \exp \left[-\frac{1}{2}(y-\sigma)^{2}\right] d y=\exp \left(\mu+0,5 \sigma^{2}\right) \cdot \beta
$$

Donde el valor de $\beta$ es 1:

$$
\beta=\left(\frac{1}{\sqrt{2 \pi}}\right) \int_{-\infty}^{+\infty} \exp \left[-\frac{1}{2}(y-\sigma)^{2}\right] d y=1
$$

A través de las ecuaciones (IV) y $(\mathrm{V})$ se tiene:

$$
E(X)=E(\exp (y))=\exp \left(\mu+0,5 \sigma^{2}\right)
$$

Así, suponiendo $x$ variable estocástica, junto con $\mu$ y $\sigma$ constantes, considerando el tiempo como una función, la ecuación (VI) queda definida como:

$$
E(x(t))=\exp \left(\mu \cdot t+0,5 \sigma^{2} \cdot t\right)
$$

Y de esta manera:

$$
\begin{array}{cc}
E(H(t))=H_{0} \cdot \exp \left(\mu \cdot t+0,5 \sigma^{2} \cdot t\right) & \forall t \geq 0 \\
E(H(t))=\frac{H_{0}}{\exp \left(\mu \cdot t+0,5 \sigma^{2} \cdot t\right)} & \forall t \leq 0
\end{array}
$$




\section{Anexo A2}

Tablas de mortalidad

Cuadro A2.1

Tablas de mortalidad correspondientes a 2009a

(Por edades en la columna de la izquierda, y en porcentajes el resto)

\begin{tabular}{|c|c|c|c|c|c|}
\hline \multirow{3}{*}{ Edad (t) } & \multicolumn{2}{|c|}{ Hombre } & \multicolumn{3}{|c|}{ Mujer } \\
\hline & \multirow{2}{*}{$Q_{t}$} & \multirow{2}{*}{$p_{t}$} & \multirow{2}{*}{$Q_{t}$} & \multirow{2}{*}{$\begin{array}{c}\text { que se jubile a los } 60 \text { años } \\
p_{t}\end{array}$} & \multirow{2}{*}{$\frac{\text { que se jubile a los } 65 \text { años }}{p_{t}}$} \\
\hline & & & & & \\
\hline 60 & & & 0,31 & 1 & \\
\hline 61 & & & 0,33 & 99,69 & \\
\hline 62 & & & 0,37 & 99,36 & \\
\hline 63 & & & 0,40 & 98,99 & \\
\hline 64 & & & 0,44 & 98,60 & \\
\hline 65 & 1,24 & 1 & 0,48 & 98,16 & 1 \\
\hline 66 & 1,36 & 98,76 & 0,53 & 97,69 & 99,52 \\
\hline 67 & 1,49 & 97,42 & 0,57 & 97,17 & 98,99 \\
\hline 68 & 1,64 & 95,97 & 0,63 & 96,62 & 98,43 \\
\hline 69 & 1,81 & 94,39 & 0,69 & 96,01 & 97,81 \\
\hline 70 & 1,99 & 92,68 & 0,76 & 95,35 & 97,13 \\
\hline 71 & 2,20 & 90,84 & 0,85 & 94,62 & 96,40 \\
\hline 72 & 2,42 & 88,84 & 0,95 & 93,82 & 95,58 \\
\hline 73 & 2,66 & 86,69 & 1,08 & 92,93 & 94,67 \\
\hline 74 & 2,92 & 84,38 & 1,23 & 91,93 & 93,65 \\
\hline 75 & 3,23 & 81,92 & 1,40 & 90,79 & 92,49 \\
\hline 76 & 3,36 & 79,27 & 1,59 & 89,52 & 91,20 \\
\hline 77 & 3,91 & 76,61 & 1,82 & 88,10 & 89,75 \\
\hline 78 & 4,31 & 73,62 & 2,08 & 86,50 & 88,12 \\
\hline 79 & 4,75 & 70,45 & 2,38 & 84,70 & 86,28 \\
\hline 80 & 5,26 & 67,10 & 2,73 & 82,68 & 84,23 \\
\hline 81 & 5,87 & 63,57 & 3,14 & 80,42 & 81,93 \\
\hline 82 & 6,56 & 59,84 & 3,60 & 77,90 & 79,36 \\
\hline 83 & 7,31 & 55,91 & 4,13 & 75,10 & 76,50 \\
\hline 84 & 8,16 & 51,83 & 4,73 & 71,99 & 73,34 \\
\hline 85 & 9,08 & 47,60 & 5,41 & 68,59 & 69,87 \\
\hline 86 & 10,07 & 43,28 & 6,17 & 64,88 & 66,09 \\
\hline 87 & 11,13 & 38,92 & 7,03 & 60,87 & 62,01 \\
\hline 88 & 12,27 & 34,59 & 7,97 & 56,60 & 57,65 \\
\hline 89 & 13,46 & 30,34 & 9,01 & 52,08 & 53,06 \\
\hline 90 & 14,17 & 26,26 & 10,14 & 47,39 & 48,28 \\
\hline 91 & 16,02 & 22,54 & 11,37 & 42,59 & 43,38 \\
\hline 92 & 17,37 & 18,93 & 12,70 & 37,74 & 38,45 \\
\hline 93 & 18,75 & 15,64 & 14,12 & 32,95 & 33,57 \\
\hline 94 & 20,22 & 12,71 & 15,64 & 28,30 & 28,83 \\
\hline
\end{tabular}


Cuadro A2.1 (conclusión)

\begin{tabular}{|c|c|c|c|c|c|}
\hline \multirow{3}{*}{ Edad (t) } & \multicolumn{2}{|c|}{ Hombre } & \multicolumn{3}{|c|}{ Mujer } \\
\hline & \multirow{2}{*}{$Q_{t}$} & \multirow{2}{*}{$p_{t}$} & \multirow{2}{*}{$Q_{t}$} & \multirow{2}{*}{$\frac{\text { que se jubile a los } 60 \text { años }}{p_{t}}$} & \multirow{2}{*}{$\begin{array}{c}\text { que se jubile a los } 65 \text { años } \\
p_{t}\end{array}$} \\
\hline & & & & & \\
\hline 95 & 21,74 & 10,14 & 17,24 & 23,87 & 24,32 \\
\hline 96 & 23,32 & 7,93 & 18,93 & 19,76 & 20,13 \\
\hline 97 & 24,93 & 6,08 & 20,72 & 16,02 & 16,32 \\
\hline 98 & 26,59 & 4,57 & 22,60 & 12,70 & 12,94 \\
\hline 99 & 28,36 & 3,35 & 24,62 & 9,83 & 10,01 \\
\hline 100 & 30,26 & 2,40 & 26,30 & 7,41 & 7,55 \\
\hline 101 & 32,26 & 1,68 & 27,71 & 5,46 & 5,56 \\
\hline 102 & 34,42 & 1,13 & 29,61 & 3,95 & 4,02 \\
\hline 103 & 36,71 & 0,74 & 31,65 & 2,78 & 2,83 \\
\hline 104 & 39,15 & 0,47 & 33,82 & 1,90 & 1,93 \\
\hline 105 & 41,76 & 0,29 & 36,15 & 1,26 & 1,28 \\
\hline 106 & 44,53 & 0,17 & 38,36 & 0,80 & 0,82 \\
\hline 107 & 47,50 & 0,09 & 41,29 & 0,49 & 0,50 \\
\hline 108 & 50,66 & 0,05 & 44,12 & 0,29 & 0,30 \\
\hline 109 & 54,02 & 0,02 & 47,16 & 0,16 & 0,17 \\
\hline 110 & 100,00 & 0,01 & 100,00 & 0,09 & 0,09 \\
\hline
\end{tabular}

Fuente: Elaboración propia, sobre la base de Superintendencia de Pensiones de Chile, "Compendio de Normas del Sistema de Pensiones, Libro III, Título X, Tablas de Mortalidad, Anexo No 5", Santiago, 2009 [en línea] http://www.spensiones.cl/ portal/compendio/596/w3-propertyvalue-4350.html.

a Para la elaboración del cuadro y, como en el resto del documento, se supone que los individuos contratan una hipoteca inversa al momento de su jubilación.

\section{Donde}

$Q_{t}=$ Probabilidad de que el individuo no esté vivo en el año $t+1$,estando vivo en $t$.

$p_{t}=$ Probabilidad de sobrevivencia o probabilidad de que el individuo esté vivo en el año $t$, habiendo estado vivo al momento de contratar la hipoteca inversa.

En el caso de las mujeres se presentan dos valores para $P_{t}$. En primer caso se brinda esta variable dada la situación de jubilación actual para el sexo femenino, que es de 60 años. Por su parte, en segunda instancia se muestra esta cifra en el escenario ficticio de que las mujeres se jubilaran a la misma edad que los hombres, es decir a los 65 años.

Por último, figura el cuadro A2.2, que muestra la probabilidad de que un individuo representativo esté vivo a una edad arbitraria representada en cada fila del cuadro, dada una edad de contratación de la hipoteca inversa de entre 65 y 80 años, lo que se observa en las columnas. Así, los valores de este cuadro corresponden al promedio geométrico de las probabilidades de sobrevivencia por sexo ponderadas por el porcentaje de cada sexo en la muestra. 
Cuadro A2.2

Tabla de probabilidades de supervivencia dependiendo de la edad en que un individuo representativo contrate la hipoteca inversa

(Por edades en la columna horizontal y en la primera columna vertical, y en porcentajes el resto)

\begin{tabular}{|c|c|c|c|c|c|c|c|c|c|c|c|c|c|c|c|c|}
\hline & 65 & 66 & 67 & 68 & 69 & 70 & 71 & 72 & 73 & 74 & 75 & 76 & 77 & 78 & 79 & 80 \\
\hline 65 & 100 & & & & & & & & & & & & & & & \\
\hline 66 & 99,2 & 100 & & & & & & & & & & & & & & \\
\hline 67 & 98,3 & 99,1 & 100 & & & & & & & & & & & & & \\
\hline 68 & 97,4 & 98,2 & 99,1 & 100 & & & & & & & & & & & & \\
\hline 69 & 96,4 & 97,2 & 98,0 & 99,0 & 100 & & & & & & & & & & & \\
\hline 70 & 95,3 & 96,1 & 96,9 & 97,8 & 98,9 & 100 & & & & & & & & & & \\
\hline 71 & 94,1 & 94,8 & 95,7 & 96,6 & 97,6 & 98,7 & 100 & & & & & & & & & \\
\hline 72 & 92,8 & 93,5 & 94,3 & 95,2 & 96,2 & 97,4 & 98,6 & 100 & & & & & & & & \\
\hline 73 & 91,3 & 92,1 & 92,9 & 93,8 & 94,7 & 95,8 & 97,1 & 98,4 & 100 & & & & & & & \\
\hline 74 & 89,8 & 90,5 & 91,3 & 92,1 & 93,1 & 94,2 & 95,4 & 96,7 & 98,3 & 100 & & & & & & \\
\hline 75 & 88,0 & 88,7 & 89,5 & 90,4 & 91,3 & 92,4 & 93,6 & 94,9 & 96,4 & 98,1 & 100 & & & & & \\
\hline 76 & 86,1 & 86,8 & 87,6 & 88,4 & 89,4 & 90,4 & 91,5 & 92,9 & 94,3 & 96,0 & 97,9 & 100 & & & & \\
\hline 77 & 84,1 & 84,8 & 85,6 & 86,4 & 87,3 & 88,3 & 89,4 & 90,7 & 92,1 & 93,8 & 95,6 & 97,7 & 100 & & & \\
\hline 78 & 81,9 & 82,5 & 83,3 & 84,1 & 85,0 & 85,9 & 87,0 & 88,3 & 89,7 & 91,2 & 93,0 & 95,1 & 97,3 & 100 & & \\
\hline 79 & 79,4 & 80,1 & 80,8 & 81,6 & 82,4 & 83,4 & 84,4 & 85,6 & 87,0 & 88,5 & 90,2 & 92,2 & 94,4 & 97,0 & 100 & \\
\hline 80 & 76,8 & 77,4 & 78,1 & 78,8 & 79,7 & 80,6 & 81,6 & 82,8 & 84,1 & 85,6 & 87,2 & 89,1 & 91,3 & 93,8 & 96,7 & 100 \\
\hline 81 & 73,9 & 74,5 & 75,1 & 75,9 & 76,7 & 77,5 & 78,5 & 79,7 & 80,9 & 82,3 & 83,9 & 85,8 & 87,8 & 90,2 & 93,0 & 96,2 \\
\hline 82 & 70,7 & 71,3 & 71,9 & 72,6 & 73,4 & 74,2 & 75,2 & 76,3 & 77,5 & 78,8 & 80,4 & 82,1 & 84,1 & 86,4 & 89,1 & 92,1 \\
\hline 83 & 67,3 & 67,9 & 68,5 & 69,1 & 69,9 & 70,7 & 71,6 & 72,6 & 73,7 & 75,0 & 76,5 & 78,2 & 80,0 & 82,2 & 84,8 & 87,7 \\
\hline 84 & 63,7 & 64,2 & 64,8 & 65,4 & 66,1 & 66,8 & 67,7 & 68,7 & 69,7 & 71,0 & 72,3 & 73,9 & 75,7 & 77,8 & 80,2 & 82,9 \\
\hline 85 & 59,8 & 60,3 & 60,8 & 61,4 & 62,0 & 62,7 & 63,5 & 64,4 & 65,5 & 66,6 & 67,9 & 69,4 & 71,0 & 73,0 & 75,2 & 77,9 \\
\hline 86 & 55,7 & 56,1 & 56,6 & 57,1 & 57,7 & 58,4 & 59,1 & 60,0 & 60,9 & 62,0 & 63,2 & 64,6 & 66,1 & 68,0 & 70,0 & 72,5 \\
\hline 87 & 51,3 & 51,7 & 52,2 & 52,7 & 53,2 & 53,9 & 54,6 & 55,3 & 56,2 & 57,2 & 58,3 & 59,6 & 61,0 & 62,7 & 64,6 & 66,8 \\
\hline 88 & 46,9 & 47,2 & 47,6 & 48,1 & 48,6 & 49,2 & 49,8 & 50,5 & 51,3 & 52,2 & 53,2 & 54,4 & 55,7 & 57,2 & 59,0 & 61,0 \\
\hline 89 & 42,3 & 42,6 & 43,0 & 43,4 & 43,9 & 44,4 & 45,0 & 45,6 & 46,3 & 47,1 & 48,1 & 49,1 & 50,3 & 51,7 & 53,2 & 55,1 \\
\hline 90 & 37,7 & 38,0 & 38,4 & 38,7 & 39,1 & 39,6 & 40,1 & 40,7 & 41,3 & 42,0 & 42,8 & 43,8 & 44,8 & 46,1 & 47,5 & 49,1 \\
\hline 91 & 33,3 & 33,5 & 33,8 & 34,2 & 34,5 & 34,9 & 35,4 & 35,9 & 36,4 & 37,1 & 37,8 & 38,6 & 39,5 & 40,6 & 41,9 & 43,3 \\
\hline 92 & 28,9 & 29,1 & 29,3 & 29,6 & 29,9 & 30,3 & 30,7 & 31,1 & 31,6 & 32,2 & 32,8 & 33,5 & 34,3 & 35,2 & 36,3 & 37,6 \\
\hline 93 & 24,6 & 24,8 & 25,1 & 25,3 & 25,6 & 25,9 & 26,2 & 26,6 & 27,0 & 27,5 & 28,0 & 28,6 & 29,3 & 30,1 & 31,0 & 32,1 \\
\hline 94 & 20,7 & 20,9 & 21,0 & 21,2 & 21,5 & 21,7 & 22,0 & 22,3 & 22,7 & 23,1 & 23,5 & 24,0 & 24,6 & 25,3 & 26,0 & 27,0 \\
\hline 95 & 17,1 & 17,2 & 17,4 & 17,5 & 17,7 & 17,9 & 18,1 & 18,4 & 18,7 & 19,0 & 19,4 & 19,8 & 20,3 & 20,8 & 21,5 & 22,2 \\
\hline 96 & 13,8 & 13,9 & 14,0 & 14,2 & 14,3 & 14,5 & 14,7 & 14,9 & 15,1 & 15,4 & 15,7 & 16,0 & 16,4 & 16,9 & 17,4 & 18,0 \\
\hline 97 & 11,0 & 11,0 & 11,1 & 11,2 & 11,4 & 11,5 & 11,6 & 11,8 & 12,0 & 12,2 & 12,4 & 12,7 & 13,0 & 13,4 & 13,8 & 14,3 \\
\hline 98 & 8,5 & 8,6 & 8,6 & 8,7 & 8,8 & 8,9 & 9,0 & 9,2 & 9,3 & 9,5 & 9,6 & 9,9 & 10,1 & 10,4 & 10,7 & 11,1 \\
\hline 99 & 6,4 & 6,5 & 6,5 & 6,6 & 6,7 & 6,8 & 6,8 & 6,9 & 7,0 & 7,2 & 7,3 & 7,5 & 7,6 & 7,9 & 8,1 & 8,4 \\
\hline 100 & 4,8 & 4,8 & 4,8 & 4,9 & 4,9 & 5,0 & 5,1 & 5,1 & 5,2 & 5,3 & 5,4 & 5,5 & 5,6 & 5,8 & 6,0 & 6,2 \\
\hline 101 & 3,4 & 3,5 & 3,5 & 3,5 & 3,6 & 3,6 & 3,6 & 3,7 & 3,8 & 3,8 & 3,9 & 4,0 & 4,1 & 4,2 & 4,3 & 4,5 \\
\hline 102 & 2,4 & 2,4 & 2,5 & 2,5 & 2,5 & 2,5 & 2,6 & 2,6 & 2,6 & 2,7 & 2,7 & 2,8 & 2,9 & 2,9 & 3,0 & 3,1 \\
\hline 103 & 1,7 & 1,7 & 1,7 & 1,7 & 1,7 & 1,7 & 1,8 & 1,8 & 1,8 & 1,8 & 1,9 & 1,9 & 2,0 & 2,0 & 2,1 & 2,1 \\
\hline 104 & 1,1 & 1,1 & 1,1 & 1,1 & 1,1 & 1,1 & 1,2 & 1,2 & 1,2 & 1,2 & 1,2 & 1,3 & 1,3 & 1,3 & 1,4 & 1,4 \\
\hline 105 & 0,7 & 0,7 & 0,7 & 0,7 & 0,7 & 0,7 & 0,7 & 0,8 & 0,8 & 0,8 & 0,8 & 0,8 & 0,8 & 0,9 & 0,9 & 0,9 \\
\hline 106 & 0,4 & 0,4 & 0,4 & 0,4 & 0,4 & 0,5 & 0,5 & 0,5 & 0,5 & 0,5 & 0,5 & 0,5 & 0,5 & 0,5 & 0,5 & 0,6 \\
\hline 107 & 0,3 & 0,3 & 0,3 & 0,3 & 0,3 & 0,3 & 0,3 & 0,3 & 0,3 & 0,3 & 0,3 & 0,3 & 0,3 & 0,3 & 0,3 & 0,3 \\
\hline 108 & 0,1 & 0,1 & 0,1 & 0,1 & 0,1 & 0,2 & 0,2 & 0,2 & 0,2 & 0,2 & 0,2 & 0,2 & 0,2 & 0,2 & 0,2 & 0,2 \\
\hline 109 & 0,1 & 0,1 & 0,1 & 0,1 & 0,1 & 0,1 & 0,1 & 0,1 & 0,1 & 0,1 & 0,1 & 0,1 & 0,1 & 0,1 & 0,1 & 0,1 \\
\hline 110 & 0,0 & 0,0 & 0,0 & 0,0 & 0,0 & 0,0 & 0,0 & 0,0 & 0,0 & 0,0 & 0,0 & 0,0 & 0,0 & 0,0 & 0,0 & 0,0 \\
\hline
\end{tabular}

Fuente: Elaboración propia, sobre la base de Superintendencia de Pensiones de Chile, "Compendio de Normas del Sistema de Pensiones, Libro III, Título X, Tablas de Mortalidad, Anexo No 5", Santiago, 2009 [en línea] http://www.spensiones.cl/ portal/compendio/596/w3-propertyvalue-4350.html. 


\section{Anexo A3}

\section{Estadística descriptiva de la muestra}

Cuadro A3.1

Estadística descriptiva de la muestra

\begin{tabular}{|c|c|c|c|c|}
\hline Variable & Media & Desvío estándar & Mínimo & Máximo \\
\hline Sexo (Hombre = 1) (en porcentajes) & 40,92 & 45,76 & 0 & 1 \\
\hline Edad & 71,22 & 7,96 & 60 & 96 \\
\hline Jefe del hogar (jefe de hogar = 1) (en porcentajes) & 65,09 & 47,68 & 0 & 1 \\
\hline Ingreso del hogar (en pesos del 2009) & 103,75 & 136,58 & 0 & 2000,00 \\
\hline Ingreso per cápita (en pesos de 2009) & 34,72 & 49,53 & 0 & 450,00 \\
\hline Índice de pobreza (en porcentajes) & 86,25 & 34,44 & 0 & 1 \\
\hline Precio vivienda imputado (en millones de pesos de 2009) & 20,40 & 4,11 & 2,50 & 50,00 \\
\hline
\end{tabular}

Fuente: Elaboración propia, sobre la base de la Encuesta de Protección Social, 2009.

Nota: Cuadro elaborado en base a 2.627 observaciones que representan a una población de 1.623 .326 individuos. 


\section{Anexo A4}

\section{Pagos de hipoteca inversa según edad de contratación}

\section{Cuadro A4.1}

Pagos de hipoteca inversa según edad de contratación

(En pesos chilenos)

\begin{tabular}{ccc}
\hline Precio de la vivienda al jubilarse & 14,00 millones de pesos de 2009 & 20,04 millones de pesos de 2009 \\
\hline Edad de contratación & Pagos mensuales Caso 1 & Pagos mensuales Caso 2 \\
\hline 65 & 62387 & 907 \\
\hline 66 & 65453 & 100166 \\
\hline 67 & 68741 & 105312 \\
\hline 68 & 72273 & 110850 \\
\hline 69 & 76074 & 116832 \\
\hline 70 & 80179 & 123297 \\
\hline 71 & 84616 & 130588 \\
\hline 72 & 89619 & 138387 \\
\hline 73 & 94972 & 146860 \\
\hline 74 & 100786 & 156031 \\
\hline 75 & 107080 & 165965 \\
\hline 76 & 113898 & 176930 \\
\hline 77 & 121423 & 188751 \\
\hline 78 & 129535 & 202790 \\
\hline 79 & 139169 & 218270 \\
\hline
\end{tabular}

Fuente: Elaboración propia, sobre la base de la Encuesta de Protección Social, 2009. 